\title{
Un enfoque cognitivo a la enseñanza de la gramática de la lengua española
}

\section{Martha Jurado Salinas* Centro de Enseñanza para Extranjeros}

\begin{abstract}
Resumen: Este artículo tiene como objetivo proponer lineamientos para desarrollar cursos de enseñanza de lengua aplicables a distintas modalidades (lengua materna y extranjera; presencial y a distancia) y a distintos niveles. La propuesta parte de una concepción del lenguaje como un sistema simbólico, adaptativo, complejo, que conecta la cognición con las partes emocionales, psicológicas, racionales, perceptuales y motrices. En ella se conjugan explicaciones gramaticales basadas en la Lingüística Cognitiva con narrativas literarias y personales (concebidas como marco o Gestalt de la experiencia propia, en el que cobran sentido dichas explicaciones).
\end{abstract}

La propuesta fue probada exitosamente en un curso en línea impartido en el Centro de Enseñanza para Extranjeros (CEPE) a profesores de español como lengua extranjera (ELE). De él se extrae como ejemplo la explicación de las preposiciones por y para. Se concluye que el objetivo fundamental de cualquier curso de lengua es desarrollar en los estudiantes una conciencia metalingüística que amplíe sus horizontes hacia conceptualizaciones que les permitan comprender la realidad y nuestra forma de ser en ella a través de la lengua.

Palabras clave: enseñanza de la gramática, Lingüística Cognitiva, preposiciones por y para.

Abstract: This article aims to propose a series of guidelines for the development of language learning courses that may be implemented in a variety of modes ( $L 1$ and L2 language learning, face to face and e-learning) and at different levels. The scheme is based on the assumption that language is a complex, symbolic, adaptive system which connects cognition with emotional, psychological, rational, perceptual and motor skills. Grammatical explanations based on

\footnotetext{
* Profesora Titular del Centro de Enseñanza para Extranjeros-UNAM. Es doctora en Lingüística por el Colegio de México. Desde 1982 ha impartido cursos de enseñanza de español a extranjeros y de formación de profesores de español. Sus líneas de investigación son la enseñanza del español, la evaluación del dominio lingüístico y el diseño de instrumentos de evaluación, y la importancia económica de la variedad mexicana del español.
} 
Cognitive Linguistics are combined with literary and personal discourses, which are regarded as a framework or existential Gestalt where these explanations become meaningful.

The scheme was successfully implemented in an online course delivered by the Centro de Enseñanza para Extranjeros (CEPE) to teachers of Spanish as a foreign language. As an example, an explanation of the use of the prepositions por and para is included. The conclusion is that the main objective of any language course is to help learners develop metalinguistic awareness which will help them widen their understanding of concepts that provide new ways of processing reality and our own vital experience through language.

Keywords: grammar teaching, Cognitive Linguistics, por and para prepositions

INTRODUCCIÓN

En el campo de la metodología de la enseñanza de lenguas extranjeras se ha suscitado en las últimas décadas un debate frente al cual los profesores debemos definir nuestra práctica, si no en términos absolutos, sí con cierto grado de precisión. La polémica se plantea en torno a si es necesario dirigir la atención de los alumnos a los rasgos formales de la lengua o si, por el contrario, los alumnos no han de fijar su atención en ellos, dado que los adquieren inconscientemente mientras están procesando input en la lengua extranjera con atención al significado.

En el marco de este dilema, el papel de la enseñanza de la gramática cobra un papel relevante (Peris, 2004), no sólo dentro del aula de enseñanza de español a extranjeros, sino, de manera más primigenia, dentro de los programas de formación de profesores de español. Aunque en general no se cuestiona que un profesor debe saber gramática -esta constituye su objeto de estudio y de trabajo-, existen también voces que aducen que los estudios de adquisición de lenguas han demostrado que la gramática tiene un efecto limitado (Krashen, 1981, 1985; Paradis, 1994). ¿Cómo justificar entonces que los futuros profesores deban aprender gramática y al mismo tiempo reconocer las evidentes limitaciones que este componente tiene tanto en su formación como en su práctica?

En este artículo trataré de dar respuesta a esta interrogante aduciendo que la aparente inutilidad de la gramática se debe a las limitaciones de su conceptualización tradicional, así como del modelo que se ha utilizado para enseñarla como lengua extranjera y como lengua materna. Analizaré 
en primera instancia las dos tendencias (externa e interna) en las que pueden agruparse las distintas maneras de conceptualizar la gramática, a fin de justificar su inclusión explícita en el aula, con pleno derecho, y sin estar supeditada ni a su función comunicativa, ni a su función de apoyo a otras disciplinas. Es decir, a partir de la concepción de la lengua como un sistema adaptativo complejo, que forma parte de nuestra cognición y cuyo conocimiento requiere del desarrollo -a través del conocimiento gramatical- de una conciencia metalingüística, justificaré el papel de la gramática, incluso dentro del enfoque comunicativo, la tendencia metodológica prevaleciente desde fines de la década de los setenta. Posteriormente analizaré las limitaciones del modelo tradicional de enseñanza de la gramática, basado en la etiquetación de categorías y distante del desarrollo de una actitud indagatoria que involucre cognitiva y afectivamente al aprendiente. Finalmente presentaré una propuesta para explicar un tema gramatical desde la perspectiva de la Lingüística Cognitiva. A partir de una concepción de lengua propia de este marco teórico, se proponen lineamientos que podrían constituir en el futuro una metodología de enseñanza de lengua tanto extranjera como materna. Como anexos se presentan ejemplos de un material didáctico que integra los conceptos de esquemas preconceptuales básicos, metáfora, narrativa y emoción y que forma parte de un curso para profesores impartido por el Centro de Enseñanza para Extranjeros (CEPE) de la Universidad Nacional Autónoma de México (UNAM).

\section{DOS TENDENCIAS EN LA CONCEPTUALIZACIÓN DE LA GRAMÁTICA}

El concepto de gramática puede ser entendido desde distintas perspectivas; por ejemplo, una de las acepciones que tradicionalmente aparece en los diccionarios lo define como"el arte de hablar y escribir correctamente una lengua" (RAE 2001). También puede ser concebida como una disciplina empírica que estudia datos lingüísticos, como un conjunto de reglas de buena formación, o como parte de un sistema adaptativo complejo que nos conforma como especie. En el primer sentido, el término remite a la concepción tradicional de la gramática como un texto que explica las llamadas "partes de la oración" o clases de palabras. Desde esta perspectiva, el objeto de estudio es la lengua "culta", razón por la cual los estudios gramaticales se encuentran ligados con los estudios literarios. La segunda acepción adopta un enfoque descriptivo que coincide en parte con la gramática tradicional, pero que, al prescindir de la normatividad, se inclina más hacia una perspectiva lingüística y científica. La tercera concepción como "conjunto de reglas de buena formación" remite a la Gramática Generativa (GG), corriente teórica que considera que la gramática implica tanto la descripción 
del funcionamiento de las distintas unidades de le lengua, como las reglas y principios generales que permiten formar palabras y oraciones. La GG se inserta en el paradigma cognitivo, dentro del cual se considera que la gramática constituye la estructura de la capacidad del lenguaje, este posee un correlato biológico ubicado en alguna parte de nuestro cerebro y está constituido, a su vez, por principios gramaticales que se manifiestan en nuestra actuación lingüística, aunque no seamos conscientes de ellos, ni seamos capaces de verbalizarlos. La cuarta acepción, ligada a la concepción del lenguaje como sistema adaptativo complejo, se inserta también en el paradigma cognitivo, pero agrega el ingrediente de la sociocomplejidad.

Las cuatro acepciones de gramática presentadas pueden distribuirse en dos grandes tendencias. Las dos primeras se ubican dentro de la concepción del saber gramatical como el estudio de una realidad externa, mientras que las dos últimas remiten a la concepción de la gramática como una parte intrínseca a nuestra cognición:

\footnotetext{
Así tenemos que el saber gramatical es, por un lado, el estudio de una realidad externa con raíces en un determinado contexto histórico, cultural y social y, por otro, el conocimiento de una realidad interna que forma parte de nuestro ser. Esta doble naturaleza de la gramática comportará que su enseñanza tenga características peculiares, no comparables con las de ninguna otra disciplina. (Lozano-Zahonero 2016: 264)
}

Como representante de la primera tendencia, la gramática tradicional describe el funcionamiento de las unidades lingüísticas y explica -con base en principios de tradición y autoridad- cómo se debe hablar una lengua; es decir, establece una serie de lineamientos del buen lenguaje, descalificando todo lo que se sale de sus límites, al considerarlo como uso local, coloquial, "no recomendado" o incluso "incorrecto". Sus prescripciones y proscripciones se remiten a cuestiones de estilo social y su alcance es relativamente limitado, ya que los hablantes, incluso aquellos con una escolaridad media, ignoran "las consignas que son ajenas a su necesidad y voluntad de significar" (Llopis, 2012: 13).

Dentro de la tendencia que considera la lengua como parte de la cognición humana, además de la GG, podemos identificar corrientes teóricas como la Lingüística Cognitiva (LC) y la Teoría de la Sociocomplejidad. A diferencia de la GG, la LC considera las conceptualizaciones lingüísticas como un producto más de nuestras facultades cognitivas generales (Llopis, 2012: 22) y postula la relación indisoluble entre forma y significado, este último definido en términos experienciales (perspectiva representacional) y visuales (imágenes esquemáticas). Por otra parte, la Teoría de la Sociocomplejidad concibe el lenguaje como un sistema complejo adaptativo. Plantea que el mundo social 
es un espacio conceptualizado activamente por el ser humano "mediante un complejo sistema simbólico generado por el lenguaje que conecta diferentes partes de la cognición con las partes emocionales y psicológicas, las racionales, las perceptuales y las motrices. Entendemos, por tanto, que el ser humano es un sistema complejo disipativo y adaptativo que establece relaciones complejas mediante el lenguaje, igualmente complejo y disipativo" (Pfleger, 2016: 2).

Las concepciones gramaticales con las que se ha operado hasta ahora en el ámbito educativo corresponden a la primera tendencia. En el aula de ELE, las explicaciones gramaticales -concebidas como un catálogo secuenciado y cerrado de estructuras predeterminadas presentadas a manera de listas de reglas y de excepciones- introducen una ruptura en relación con el trabajo dinámico, colaborativo y lúdico de las habilidades lingüísticas. Al llegar el momento de abordar la gramática, incluso la disposición del espacio es diferente, los alumnos entienden que deben volver su vista hacia el pizarrón, porque el profesor va a explicar gramática, generalmente basado en un texto en el cual, en pequeños recuadros, en un color ligeramente diferente o en páginas separadas, "se administra en dosis pequeñas, discretas, mutiladas de un sistema del que no quedan huellas y definidas con un criterio tan ajeno a su capacidad de significar que acaban flotando como gotitas de agua sobre el espeso aceite de la comunicación en el aula" (Llopis, 2012: 10).

Esta simplificación dificulta la tarea de profesor, quien generalmente no encuentra una explicación satisfactoria de los complejos fenómenos que surgen en un aula multilingüe, particularmente cuando los actores son personas adultas con capacidad para contrastar las explicaciones con sus propios sistemas lingüísticos: "La bibliografía no nos saca de dudas y nosotros mismos nos embrollamos con explicaciones laberínticas de formas, significados, contextos y expresiones, pragmática, semántica o sintaxis. ¿Por qué es tan complicada la gramática? ¿qué la hace ser tan inaccesible y qué la convierte en el 'punto caliente' del mundo de ELE moderno y al día, es decir, en el aula comunicativa?" (Llopis, 2012:10). En suma, en el aula de ELE se trabaja con precarias explicaciones gramaticales de corte tradicional, enunciadas a manera de listas, las cuales se pretende que el alumno memorice y aplique correctamente en distintos contextos de uso.

En nuestro país, los contextos educativos en los que se enseña español como lengua materna son muy diversos (Munguía 2014; Díaz et al., 2014). En la mayoría de ellos predomina el enfoque comunicativo, con la consecuente supeditación de algunos rudimentos gramaticales (provenientes de la gramática tradicional) a un trabajo de corte pragmático y discursivo aplicado a diferentes géneros textuales. 
En los cursos de redacción, las dispersas explicaciones gramaticales -muchas de ellas de corte normativo- se abordan como una técnica de sobrevivencia. La lengua es un instrumento y los hablantes sus usuarios. No se trata de aprender sobre la lengua ni de conocer su funcionamiento, sino de usarla para escribir textos adecuados a diferentes géneros, y que cumplen distintas funciones comunicativas.

Esta concepción se basa en la oposición contenidos de usuario vs. contenidos de experto. Se considera que la finalidad no es que los estudiantes sean lingüistas, sino que usen la lengua para comunicarse, razón por la cual no se deben mencionar «conceptos técnicos» tales como concordancia, sujeto, perífrasis verbal, etc., ya que estos constituirían contenidos de experto. El problema es que resulta difícil entender y autocorregir lengua escrita sin una dotación mínima de conocimiento gramatical: "En general, resulta casi imposible abordar, de manera no trivializada, la simple identificación de unidades en la gramática básica si la fundamentamos en la distinción Contenidos de usuario vs. Contenidos de experto. La razón radica en que el más elemental proceso categorizador ya contiene, aunque sea implícitamente, cierto contenido teórico" (Bosque 2014: 7).

La visión externa de la lengua ha prevalecido en nuestro país en las últimas décadas, incluso después de la modificación a los planes y programas de estudio para la enseñanza primaria y secundaria implantada por la Secretaría de Educación Pública (SEP) en 2006, a partir de la cual se replantearon los contenidos lingüísticos, se introdujeron modificaciones en relación con la incorporación de las nuevas tecnologías, se puso énfasis tanto en el aprovechamiento de los materiales de lectura en las aulas, como en la vinculación y apoyo de la lengua a las diferentes áreas del conocimiento (Díaz et al., 2014: 181-182). El tratamiento de la lengua en el nuevo modelo educativo que entrará en vigor a partir del ciclo escolar 2018 todavía está por verse. Sería deseable que el desarrollo de la competencia general de "aprender a aprender" se vinculara con el desarrollo de una conciencia lingüística y metalingüística y no solo con la competencia comunicativa, entendida como se ha hecho hasta ahora.

Otro problema derivado de la visión instrumental y parcializada es la actitud de rechazo que los estudios gramaticales generan entre profesores y estudiantes. Recuerdo alguna ocasión en la que tuve que dar un curso de gramática a profesores de «Talleres de redacción» de nivel medio superior. Para convencerlos de la pertinencia del curso (objetivo que no logré), les pedí que corrigieran y retroalimentaran muestras auténticas de lengua escrita producidas por sus estudiantes. La mayoría de ellos (provenientes de la carrera de Comunicación) marcaban los errores, pero no los explicaban o recurrían a recomendaciones del tipo "Les diría que leyeran a los autores clásicos". Sobra decir que difícilmente los estudiantes podrán mejorar su expresión escrita si 
no cuentan con los conocimientos lingüísticos para analizar, comprender y autocorregir sus errores. Esta actitud renuente de los docentes reduce el goce que podría implicar hacer de su práctica un espacio de descubrimiento y dominio de ese sistema complejo que compartimos como especie:

En lugar de resaltar y potenciar el análisis de su riqueza, su versatilidad, su articulación interna, su plasticidad, su sutileza, su variación y su capacidad expresiva, se fomenta a menudo el aprendizaje mecánico del código prescriptivo con el que se lo suele asociar, sin fundamentarlo en la base gramatical en la que todas esas normas cobran sentido. (Bosque y Gallego, en prensa: 15)

En el caso de cursos específicamente enfocados a la lengua española, por ejemplo, en las carreras de Letras hispánicas o en los cursos de profesores de ELE, la concepción gramatical también corresponde a la primera tendencia. Se trabaja con una combinación de gramática tradicional aderezada -en el mejor de los casos- con los avances lingüísticos incorporados en las distintas versiones de la Nueva Gramática de la Lengua Española, publicadas en la última década por la Real Academia Española (RAE), en colaboración con la Asociación de Academias de la Lengua Española (ASALE). Como puede apreciarse, aunque se trata de ámbitos de expertos y no de usuarios, la visión de la gramática no varía.

En contra de la visión externa e instrumental de la enseñanza de la lengua española se han alzado en tiempos recientes diversas voces, como la de Munguía $(2014,2016)$ y la de Ignacio Bosque (1994, 2011, 2014, 2015, 2016), quien afirma que los profesores de lengua hemos fallado en hacer conscientes a los estudiantes de que la gramática no constituye un saber externo (como podrían ser los contenidos de un curso de geografía), sino un conocimiento que viene de lo más profundo de nosotros mismos:

Cuando el profesor de ciencias naturales explica en clase la estructura del corazón humano, el alumno sabe que le están hablando de su corazón.

Cuando el profesor de lengua explica en clase la estructura de las subordinadas sustantivas, el alumno no piensa ni por un momento que le estén hablando de sus subordinadas sustantivas. (Bosque, 2015: 22)

En suma, la concepción externa de la lengua que da origen a la analogía instrumental no resulta apropiada para el estudio de la lengua, simplemente porque "no somos usuarios de nosotros mismos" (Bosque y Gallego, en prensa: 17), sino que, como afirma Maturana (1996), "somos en el lenguaje y a través de él".

Las disertaciones de Bosque apuntan hacia la segunda tendencia de conceptualización de la gramática como un sistema interiorizado, patrimonio personal de cada individuo, rico en matices y en capacidades expresivas; "un 
entramado de piezas léxicas, construcciones y relaciones que permiten a cada hablante crear pensamientos, articular juicios y expresar emociones de forma enteramente libre" (Bosque y Gallego, en prensa: 43).

En esta segunda tendencia, la lengua se conceptualiza como una parte integrante de nuestras estructuras psíquicas que mediatizan nuestra interacción con el mundo; es la herramienta que nos permite conocerlo y acceder a otros mundos a través de la metáfora (Tolchinsky, 2011). Pero no solo es una herramienta que vehicula nuestro conocimiento del mundo, sino también que nos permite reflexionar sobre nuestras actuaciones y sobre la lengua misma, a través del desarrollo de la conciencia metalingüística. Esta singular capacidad autorreferencial nos posibilita considerar la lengua misma como objeto de estudio, analizarla más allá de su función habitual de comunicación, manipularla y reflexionar sobre ella (Perales 2014). Cabe aclarar que, aunque el hecho de tener cierta conciencia metalingüística no implica necesariamente conocer teorías lingüísticas o términos gramaticales complejos, es un hecho que los máximos niveles de conciencia metalingüística aparecen asociados siempre a altos niveles de alfabetización y de formación lingüística.

Concebido desde la perspectiva de esta segunda tendencia, el estudio de la gramática en el aula estaría plenamente justificado, puesto que se trata de un conocimiento valioso en sí mismo (no solo un instrumento al servicio de otras disciplinas), que implica "un ejercicio reflexivo de sistematización, el cual coadyuva al desarrollo de las capacidades cognitivas y al robustecimiento de la reflexión y el pensamiento complejo del individuo" (Munguía, 2016: 15). Además, la capacidad metalingüística fomenta la autonomía y el pensamiento crítico (Lozano-Zahonero, 2016); facilita el aprendizaje de segundas lenguas; desarrolla un sistema de alerta que permite monitorear la propia producción oral y escrita constituyendo de esta manera "el punto de partida para el análisis del discurso, dado que ayuda a la tarea de discurrir acerca de cómo se articulan y se enlazan las grandes estructuras complejas del texto" (Munguía, 2016: 15).

El reto radica en formar profesores que sepan suscitar en sus estudiantes -a través de una actitud de reto y descubrimiento- una pasión que los conduzca a comprender que se trata de sus subordinadas, de sus adjetivos, de sus matices semánticos y de sus intenciones; en suma, de su forma de ser en el mundo. A partir del logro de este objetivo primigenio, se facilitaría el aprendizaje de todos los demás conocimientos que hemos tratado de inculcar de manera forzada en la educación formal (hábitos y comprensión de lectura, vocabulario, capacidad de expresión, escritura adecuada de distintos géneros textuales, etcétera).

Finalmente, cabe señalar que la multidimensionalidad intrínseca a la lengua, es decir, el hecho de que puede ser analizada en diferentes niveles, componentes o dimensiones que ocurren simultáneamente, la convierte en un aprendizaje para 
toda la vida. Nunca dejamos de aprender sobre ella, cada texto que escribimos o que leemos, cada intervención oral que producimos o escuchamos, cada intercambio comunicativo es susceptible de ser analizado, la cuestión es que nunca se nos ha inculcado una actitud indagadora y heurística que pueda despertar el apasionante reto de expresarnos y descubrirnos a nosotros mismos a través de lo que decimos. Este último punto nos lleva a la siguiente sección, en la que analizaremos las limitaciones del modelo metodológico aplicado en nuestro país a la enseñanza del español, como lengua extranjera y como materna.

\section{TendenCiAS METOdolóGICAS EN LA ENSEÑANZA DE LA GRAMÁtICA}

El predominio de la conceptualización de la gramática como un conocimiento instrumental y externo se corresponde con un tratamiento metodológico que privilegia el uso de la lengua y que ha dado lugar al malentendido de su inutilidad en el aula, y en general en el currículo escolar. En esta segunda sección repasaremos los enfoques metodológicos que se han aplicado en las últimas décadas, tanto en la enseñanza de lenguas extranjeras en general, como en la enseñanza de español como lengua materna, a fin de mostrar su limitación para desarrollar un conocimiento lingüístico y metalingüístico valioso per se e indispensable para lidiar con las exigencias de la vida académica.

El papel que ha ocupado gramática ha variado a lo largo de la historia de los enfoques metodológicos aplicados en la enseñanza de lenguas. Desde fines de los años 70, predomina en este campo el Enfoque Comunicativo (EC). Durante mucho tiempo se interpretó que, puesto que este enfoque privilegia la enseñanza de la lengua en uso y la comunicación en su contexto, la gramática quedaba supeditada o definitivamente desterrada del aula.

La proscripción de uso de la gramática tiene su origen en una interpretación extrema del concepto fundacional del EC: el concepto de «competencia comunicativa» (CC), entendido como "la capacidad de las personas para comportarse comunicativamente de manera eficaz y adecuada en una comunidad de habla" (Lomas, 2014: 37). La CC se traduce en una metodología que orienta la enseñanza del lenguaje hacia las destrezas y las habilidades, incorporando la diversidad de la lengua en uso y enfatizando su carácter social, a partir del texto como unidad mínima de comunicación.

Dicho concepto surgió en 1972, cuando Hymes amplió el concepto chomskiano de «competencia lingüística» postulando que, más que un conjunto de reglas que se combinan para formar oraciones gramaticales, lo importante es el uso que hacemos de esas reglas en un contexto concreto y específico en 
cuanto a qué se dice, cuándo se dice, dónde se dice y a quién se dice. Hymes denominó a este concepto ampliado «competencia comunicativa».

A partir de Hymes, el concepto se ha desarrollado en función de modelos que intentan describir los componentes implicados en el conocimiento de una lengua, su interrelación y las destrezas que una persona necesita para comunicarse eficaz y apropiadamente. Entre los modelos más representativos están el de Canale y Swain (1981) y el modelo funcional de Bachman (1990).

Canale y Swain (1981) identifican cuatro dimensiones de la competencia comunicativa:

8. Competencia gramatical. Puede definirse como el dominio de la capacidad gramatical y léxica.

9. Competencia sociolingüística. Se refiere a la comprensión del contexto social en el que tiene lugar la comunicación, incluyendo la relación entre los distintos papeles sociales, la información que comparten los participantes y la finalidad comunicativa de su interacción.

10. Competencia discursiva. Se refiere a la interpretación de los elementos individuales del mensaje a partir de sus conexiones y de cómo se representa el significado en relación con todo el discurso o texto.

11. Competencia estratégica. Ser refiere a las estrategias que los participantes de la interacción emplean para iniciar, mantener, terminar, corregir y reconducir la comunicación.

En el modelo más elaborado, analítico y funcional de Bachman, la competencia gramatical incluye el conocimiento del vocabulario, la morfología, la sintaxis y la fonología/grafología. Implica la selección de palabras para expresar significados específicos, sus formas, el orden de las oraciones para expresar proposiciones y su realización física ya sea oral o escrita. Se trata de un constructo teórico relacionado con el campo de la evaluación lingüística.

Como puede apreciarse, el componente gramatical forma parte fundamental de todos los modelos de competencia comunicativa y ésta, a su vez, constituye el concepto fundacional del Enfoque Comunicativo; por tanto, es una falacia afirmar que dicho enfoque proscribe la enseñanza de la gramática o que, porque se adopta el EC, no se debe enseñar gramática.

El destierro de la gramática del aula de ELE ha sido también acreditado con base en argumentos procedentes del campo de la adquisición de lenguas. Desde esta perspectiva se ha argumentado que:

a) El conocimiento gramatical explícito es fácilmente olvidable en plazos que algunos autores calculan en un promedio de tres meses. 
b) Las formas correctas aparecen exclusivamente en situaciones controladas y monitorizadas, mientras que en los contextos libres persisten los errores.

c) La adquisición de formas complejas es inmune a este tratamiento pedagógico.

d) El desarrollo del proceso de la interlengua, -es decir, la estructura psicológica latente que se acciona durante la adquisición/aprendizaje de una lengua extranjera y cuyas reglas no corresponden ni a las de la lengua materna ni a las de la extranjera (Selinker, 1972)- está claramente limitado por el orden natural de adquisición, de manera que si la estructura en cuestión no se encuentra graduada al nivel de los alumnos, su efecto en el aprendizaje es nulo.

A pesar de todas estas objeciones, se admite también que:

Los resultados de la investigación dentro del paradigma AF/AS [Atención a la forma/ Atención al significado] no permiten hacer generalizaciones taxativas, hasta el punto de descartar que cualquiera de los tipos de conocimiento tratados redunde en el incremento de la competencia gramatical o comunicativa de la lengua. (Lorenzo, 2004: 37)

Es decir, aun dentro del campo mismo de la Psicolingüística, resulta imposible descartar absolutamente la introducción de la gramática en el aula de ELE, entre otras razones, por la falta de contundencia de los estudios de adquisición. Hay que admitir, por otra parte, que estos contra-argumentos resultan válidos principalmente en relación con la adquisición de la lengua oral, la cual se caracteriza por desarrollarse en tiempo real, privilegiar la fluidez sobre la precisión, y estar sujeta a las vicisitudes del contexto (que incluyen factores como la fatiga mental del hablante). Lo importante es que el mensaje llegue, y para ello se echa mano de recursos extra-lingüísticos que compensan la posible falta de precisión gramatical.

Sin embargo, debe tenerse en cuenta que muchos de los alumnos que estudian una lengua lo hacen con fines no sólo de comunicación oral, sino también con fines académicos o laborales. En estos casos, se enfrentan a la necesidad de producir textos escritos de muy diversa índole. Sin embargo, -como también admite el EC- no es suficiente adecuarse a una superestructura textual, los textos también deben presentar atributos en el nivel microestructural, como la precisión gramatical, la riqueza léxica, la cohesión, etc. Es entonces cuando la reflexión gramatical, aunada al uso del diccionario, rinde sus frutos. El trabajar un texto escrito brinda la posibilidad de reflexionar y recurrir al conocimiento gramatical que en algún momento se aprendió en los libros o en las clases formales. Aunque este conocimiento reflexivo no llegue a hacerse productivo 
en la lengua oral -lo cual depende de múltiples e impredecibles factores, entre ellos, los diversos estilos de aprendizaje de los alumnos- constituye un conocimiento pasivo del que el alumno puede echar mano según sus necesidades de producción de textos escritos.

Para conciliar la enseñanza de la forma gramatical con el desarrollo de la competencia comunicativa y con la enseñanza centrada en el alumno, se han desarrollado metodologías aplicadas a la enseñanza de ELE, como el "Procesamiento del Input" (Lee y Van Patten 1995, Van Patten 1996), la "Atención a la forma" (Focus on form) (Dooghty y Williams, 1998, Long 1991). Ambas coinciden en dirigir la atención a la forma, pero dentro de una actividad que se centra en el significado. La Teoría del input estructurado vincula la teoría y la investigación sobre adquisición de segundas lenguas con un tratamiento pedagógico. Propone lineamientos muy concretos para el diseño de actividades (enseña solo una cosa a la vez, mantener la atención en el significado, hacer algo con el input, utilizar input oral y escrito, ir de la oración al discurso, aplicar estrategias de procesamiento psicolingüístico, etc.). La Atención a la forma también centra la atención primero en la comprensión del significado, para pasar después a la comprensión lingüística. Se trata de que los alumnos descubran deductivamente la forma lingüística después de haber comprendido, en una actividad comunicativa, el contenido de las muestras lingüísticas.

Este breve recorrido por algunas metodologías de enseñanza de ELE evidencia dos puntos: la gramática no ha podido ser desterrada del currículo de ELE porque en el fondo, aun los enfoques metodológicos que privilegian la comunicación o el procesamiento del lenguaje a través del significado, nunca han prescindido de ella. Otra prueba de esta persistencia latente es que de manera casi paralela al EC, se ha desarrollado en la enseñanza del inglés enfoques como el de "conciencia lingüística" (Language awareness), el cual postula que tanto la conciencia metalingüística como la conciencia metacognitiva constituyen un prerrequisito para un desempeño académico adecuado, para desarrollar un currículo centrado en el alumno y para fomentar su autonomía:

Language awareness blends a) content about language, b) language skill, c) attitudinal education and d) metacognitive opportunities, which allow the student to reflect on the process of language acquisition, learning and language use. All four of these aspects of language awareness need to be integrated into the existing subject areas. A focus on language awareness is a key aspect of creating student-centered classrooms, and assists the teacher to present material accordingly to student readiness (Bilash and Tulasiewicz, 1995: 49).

El segundo punto que se evidencia es que hasta la fecha no existe un método infalible, ni una respuesta contundente respecto a la utilidad o inutilidad de la gramática en el aula de ELE. En este sentido, es importante que el 
profesor entienda que las metodologías de enseñanza no funcionan de manera sustitutiva, sino acumulativa. Aspectos de cada una de las distintas metodologías pueden ser retomados en distintos momentos del proceso de enseñanza, dependiendo de factores como el contexto, las necesidades y los estilos de aprendizaje de los alumnos. El proceso de cada grupo determina la cantidad y profundidad de las explicaciones gramaticales que se requieren. No se trata de organizar las clases con base en un catálogo secuenciado y cerrado de estructuras predeterminadas, sino de planear a la par de las actividades que privilegien el uso de la lengua, otras que permitan la reflexión sobre la misma. Además, el profesor debe estar preparado no solo para corregir errores, sino también para aclarar las dudas que puedan surgir respecto al funcionamiento del sistema lingüístico, suministrando explicaciones que resulten significativas para los estudiantes.

Finalmente, cabe señalar que, específicamente en los contextos multilingües de personas adultas que aprenden español, surge de manera natural la reflexión metalingüística. El contraste con sistemas lingüísticos propios de los estudiantes es inevitable. Por esta razón, es deseable que el profesor de ELE conciba la gramática como un sistema adaptativo complejo e inherente a nuestra naturaleza, que se apasione por la lengua y que desarrolle una conciencia metalingüística que lo posibilite para, si no dar respuesta inmediata a las dudas de los estudiantes, al menos tener los elementos teóricos que les permitan reflexionar, investigar en fuentes confiables y aventurar posibles explicaciones. La respuesta "porque así es el español" resulta inadmisible en un profesional de la enseñanza, como los que aspiramos egresar de nuestros cursos de formación.

Por lo que respecta a la enseñanza de español como lengua materna, en los niveles básicos y medio superior también fue implantado en la década de los 90 el enfoque comunicativo:

... se tomó la decisión de introducir una nueva perspectiva y se adoptó un enfoque que ya había sido probado, en otros países, en la enseñanza de segundas lenguas y de lenguas extranjeras: el enfoque comunicativo y funcional. En 1993 se elaboraron nuevos programas desde esta perspectiva (SEP, 1993). Se diseñaron libros de texto y se modificó la formación del profesorado. (Díaz et al. 2014: 178).

Por tanto -al igual que en el aula de ELE-, la metodología se basa en el diseño de actividades enfocadas en el uso de la lengua y en las que se prescinde de explicaciones gramaticales, o en las que estas aparecen supeditadas a la escritura de distintos géneros textuales, a manera de información inconexa y desprendida del sistema en el cual cobran sentido. En el caso de los estudios superiores especializados, la metodología consiste -a grandes rasgos- en 
clasificar y etiquetar con términos abstrusos pertenecientes a distintos marcos teóricos, los constituyentes y las funciones sintácticas que desempeñan.

El cambio hacia una concepción de la gramática como estructuradora de nuestro sistema cognitivo requeriría del desarrollo de una metodología similar a la que se utiliza para resolver problemas en el área científica. Para alcanzar este objetivo, Bosque y Gallego (en prensa) proponen diseñar actividades y ejercicios que encaucen la curiosidad natural de los jóvenes, que los reten a descubrir ese sistema interno mediante a) la observación de los aspectos del idioma que parecen más simples e inmediatos, b) la relación de causas y efectos, c) la generalización, d) la experimentación, e) la argumentación y f) la contraargumentación. Los autores citados proponen un catálogo de ejercicios que pueden contribuir a desarrollar esa actitud heurística hacia la lengua: pares mínimos, análisis inverso, propuestas de ejemplos con base en esquemas, reflexión sobre errores y sobre posibles excepciones, contraejemplos a las generalizaciones gramaticales que proporcionan los libros de texto, etc.

Como puede apreciarse, existe una correlación entre la concepción de la gramática como un sistema impuesto desde fuera y las metodologías de enseñanza basadas en el uso de la lengua (concepción instrumental) o en actitudes normativistas y etiquetadoras (en el caso de la enseñanza de la lengua como contenido de experto). La tendencia a considerar la gramática como estructuradora de nuestra cognición no va aparejada con una metodología de enseñanza definida como tal; hasta el momento se cuenta solamente con algunos textos teóricos que contienen sugerencias de actividades y modelos de ejercicios, y un manual de práctica (Gramática Básica para el estudiante de español). El ejemplo que se presenta en la siguiente sección propone lineamientos para avanzar en la construcción de una metodología cognitiva de enseñanza de ELE.

III. PROPUESTA PARA SUPERAR LAS LIMITACIONES DE LAS CONCEPTUALIZACIONES DE LA GRAMÁTICA Y DE SU METODOLOGÍA DE ENSEÑANZA

En esta tercera sección se presenta una unidad didáctica que incluye un modelo de explicación gramatical que retoma conceptos básicos de la Lingüística Cognitiva (LC). Cabe aclarar que esta es una teoría lingüística, no de una teoría de lingüística aplicada a la enseñanza, por tanto, su inclusión en el aula constituye una herramienta de instrucción gramatical explícita, no un método de enseñanza. El ejemplo que se bosqueja forma parte de un curso en línea dirigido a profesores de enseñanza de ELE. Se anexan además la versión impresa de un fragmento del curso y un ejemplo de una participación en foros. 
Como se mencionó en la sección I, la Lingüística Cognitiva se inserta en la segunda tendencia de conceptualización de la gramática como un sistema adaptativo complejo que forma parte de nuestro ser. Abordar la lengua desde esta perspectiva teórica conduce a reflexionar sobre ese sistema que compartimos no solo con hablantes de nuestra propia lengua, sino con los hablantes de otras lenguas; es decir, conduce al desarrollo de una conciencia metacognitiva.

La LC postula como eje fundamental la indisoluble relación entre forma y significado. Es decir, se trata de una gramática de carácter semántico cuya unidad básica no es la forma en sí misma, ni el significado en sí mismo, sino una unidad simbólica en la que forma y significado (significado conceptual) son inseparables. Dicha indisolubilidad trae aparejada la concepción de que los niveles de la lengua, particularmente el léxico y la gramática, forman un continuum, en el que todos los elementos son de naturaleza simbólica; de ahí se desprende el postulado de que todos los elementos gramaticales son significativos" (Langacker 2001: 6). Evans la caracteriza de esta manera:

Cognitive linguistics is a modern school of linguistic thought that originally emerged in the early 1970 s. It is also firmly rooted in the emergence of modern cognitive science

in the 1960s and 1970s, particularly in work relating to human categorization, and in earlier traditions such as Gestalt psychology. Cognitive linguistics is primarily concerned with investigating the relationship between language, the mind and socio-physical experience. (Evans, 2007: vi).

La Lingüística Cognitiva concibe al menos dos tipos de estructuras provenientes de nuestra experiencia física y conformadas durante los primeros días de la vida de un ser humano:

1. Estructuras de nivel básico, cuyas categorías se definen por la convergencia de nuestra percepción gestáltica, nuestra capacidad para el movimiento corporal y nuestra habilidad para formar ricas imágenes mentales.

2. Esquemas de imágenes kinestésicas, es decir, estructuras simples que son recurrentes en nuestra experiencia corporal diaria y que proyectamos para elaborar estructuras, proposiciones, conceptos y estructuras organizadas de datos. Algunos ejemplos son los esquemas de contenedor, caminos, enlaces, fuerzas, equilibrios, orientaciones y relaciones, etc. 
Muñoz (2006: 16) explica que estas estructuras responden a capacidades cognitivas básicas que podemos observar en nosotros mismos:

1. Podemos experimentar un cierto rango de colores, tonos, gustos, olores y sensaciones táctiles.

2. Tenemos noción de la extensión espacial y de configuraciones espaciales.

3. Sentimos el paso del tiempo.

4. Experimentamos un conjunto de emociones.

5. Tenemos varias habilidades cognitivas que son aplicables a cualquier dominio de experiencia y que son esenciales para la emergencia de conceptos específicos en sucesivos niveles de complejidad organizativa:

5.1. Podemos comparar dos experiencias y registrar la similitud o diferencia entre ellas.

5.2. Podemos usar una estructura como base para categorizar otra.

5.3. Tenemos capacidad de abstracción (esquematización) y con ella concebimos situaciones que varían en grado de especificidad o de detalle.

5.4. Somos capaces de dirigir y enfocar nuestra atención, y de estructurar escenas en términos de una organización figura/ fondo (que puede ser reversible).

5.5. Tenemos la habilidad de establecer relaciones, es decir, de concebir entidades en conexión con otras.

5.6. Somos capaces de agrupar un conjunto de entidades en función de su similitud, proximidad o alguna otra relación y manipular ese grupo como una entidad unitaria para propósitos de orden superior. Este proceso dual de agrupamiento y manipulación produce una conceptualización de entidades como cosas abstractas («reificación conceptual») que pueblan nuestro mundo mental y que son expresadas mediante nombres.

5.7. Tenemos la capacidad de rastrear caminos mentales a través de estructuras complejas, lo cual nos permite una gran flexibilidad conceptual.

5.8. Podemos analizar secuencialmente una estructura estática o podemos ver situaciones cambiantes de forma holística.

5.9. Proyectamos semejanzas y experiencias en procesos metafóricos y metonímicos. Procesos de gran importancia cognitiva presentes en nuestras expresiones cotidianas y no solo en textos de carácter literario.

De la proyección de estas estructuras básicas provenientes de nuestra experiencia preconceptual en la lengua surge el concepto de corporización (embodiment of language): 
... the concept of embodiment of language, we refer to Lee (2001: 18), when he states that "one of our earliest and most basic cognitive achievements as infants is to acquire an understanding of objects and of the way in which they relate to each other in physical space." From a very early age, and well before we can begin uttering words, we attain an understanding of our surroundings and become able to signal things of interest, differentiate between up and down, or understand what is within or without our immediate reach. In time, our own perception and our body's interaction with the world will shape how we verbalize our thoughts. (Llopis-García, 2016: 36)

En la construcción de la propuesta didáctica que presentaremos en la siguiente sección a manera de ejemplo, retomamos específicamente los conceptos cognitivos de «estructuras básicas» provenientes de nuestra experiencia preconceptual y de «metáfora». Las estructuras básicas se relacionan estrechamente con la corporeidad y se manifiestas en esquemas como figura/ fondo, origen trayectoria- meta, contenido-continente, dinámica de fuerzas, etc.

La metáfora constituye el recurso cognitivo por excelencia para comprender la realidad y compartirla porque "it enables the 'translation' of our very abstract mind and thinking processes into comprehensible linguistic terms that our peers may understand" (Llopis-Gracía (2916: 45). Las metáforas pueden ser lingüísticas o conceptuales. Estas últimas se definen como

A form of conceptual projection involving mappings or correspondences holding between distinct conceptual domains. Conceptual metaphors often consist of a series of conventional mappings which relate aspects of two distinct conceptual domains. The purpose of such a set of mappings is to provide structure from one conceptual domain, the source domain, by projecting the structure onto the target domain. This allows inferences which hold in the source to be applied to the target. For this reason, conceptual metaphors are claimed to be a basic and indispensable instrument of thought. (Evans 2007: 137)

El término mapeo proviene de las matemáticas y se refiere a las correspondencias metafóricas sistemáticas entre ideas estrechamente relacionadas. Los dominios conceptuales son estructuras de conocimiento (experiencias mentales, espacios representacionales o conceptos) necesarias para caracterizar semánticamente una expresión lingüística o unidad semántica.

Las metáforas lingüísticas, por otra parte, "will be responsable for expressing those thoughts with specific words and will account for differences across languages, where diverse constructions and linguistic items are selected to express a construal, sometimes even from different point of view" (Llopis-García: 2016: 45-46).

La LC postula que nuestra cognición funciona con base en metáforas (muchas de ellas relacionadas con nuestra corporeidad) y en estructuras, conformadas durante las primeras semanas de vida, que responden a capacidades cognitivas 
básicas. Estas estructuras básicas -como ya mencionamos- se definen por la convergencia de nuestra percepción gestáltica, nuestra capacidad para el movimiento corporal y nuestra habilidad para formar imágenes mentales enriquecidas. Se trata de estructuras simples, recurrentes en nuestra experiencia corporal diaria, y que proyectamos para elaborar estructuras, proposiciones, conceptos y estructuras de datos organizadas.

Por su raigambre en la estructura cognitiva compartida por los seres humanos, estos y otros conceptos de la LC («redes semánticas», «estructuración del significado» o «estructuración conceptual» (construal), «prototipos», «perspectiva» o "punto de vista» y «elementos visuales») conforman una herramienta particularmente idónea para diseñar materiales que incorporen el conocimiento lingüístico y metalingüístico en el aula, de manera accesible y casi intuitiva.

\section{III.2. Propuesta de UnA CONCEPCIÓN MEtodológICA QUe INTEGRA ELEMENTOS COGNitivos}

La concepción cognitiva de la gramática posibilita que los profesores empiecen a resolver el dilema metodológico entre el enfoque comunicativo y la enseñanza de la gramática, porque concibe al usuario de la lengua como el conceptualizador que toma las decisiones sobre cómo decir aquello que quiere comunicar, en función de sus intenciones. Es decir, la lengua representa la realidad tal y como el sujeto la percibe y quiere que la perciba el oyente; por tanto, está destinada a favorecer diferentes perspectivas representacionales de un mismo hecho "objetivo". En este sentido, se trataría de una lógica natural, basada en los esquemas cognitivos con los que construimos la representación humana del mundo; una lógica de "sentido común". "Ahí donde un alumno pregunte el por qué delatando su necesidad de encajar lógicamente lo aprendido, un enfoque cognitivo provee de nuevos instrumentos para que ello sea posible." (RuizCampillo, 2007: 13).

Otra ventaja de la perspectiva cognitiva -según Ruiz-Campillo- es entender la gramática del español como una simple manifestación particular de representación del mundo, de la que cada alumno puede ser consciente pensando en su propia lengua. Además, la LC"ha hecho un uso extensivo del lenguaje visual para desarrollar sus análisis lingüísticos, modulando y facilitando el acceso al contenido metalingüístico abstracto con el que opera" (Romo: 2015:13).

Finalmente, cabe reiterar que, puesto que se trata de una herramienta de instrucción gramatical explícita, no un método de enseñanza, es compatible con otros modelos tanto teóricos como metodológicos: 
No es incompatible, a pesar de todo, con otros modelos descriptivos, porque estos se sitúan en planos diferentes de análisis. Categorías, que, en modelos tradicionales resultan adecuadas para describir el funcionamiento de los componentes de la oración, por ejemplo, pueden complementarse con principios operativos de corte cognitivo en el plano del discurso (Fornés, 2013: 425)

Debido a las características mencionadas, la LC ha dado frutos interesantes en el diseño de materiales didácticos dirigidos a estudiantes extranjeros. Aunque se cuenta ya con manuales que incluyen explicaciones de corte cognitivo en conjunción con metodologías que siguen lineamientos acordes con la teoría de la adquisición de lenguas (por ejemplo Alonso, et al. 2005 [2015], Castañeda, 2014; y Llopis, 2011), no existe un método de enseñanza de lengua que pudiera considerarse integralmente cognitivo. En un intento por avanzar en propuestas de esta índole, se diseñó en 2016, en el Centro de Enseñanza para Extranjeros (CEPE) de la Universidad Nacional Autónoma de México (UNAM) un curso en línea de Gramática Cognitiva (GC), dirigido a profesores de ELE.

El curso de GC consta de cinco unidades. En las tres primeras se plantean conceptos teóricos (el papel de la gramática en la construcción del significado, estructuras básicas provenientes de nuestra experiencia preconceptual y características semánticas de las categorías sustantivo y verbo), mientras que en las dos últimas se explican cuatro temas característicos del español con base en conceptos de la LC (las preposiciones pory para, el modo subjuntivo, el pretérito y el copretérito y los verbos haber, estar y ser). Las actividades de las dos últimas unidades tienen como objetivo reflexionar sobre el desarrollo de materiales didácticos con explicaciones gramaticales de corte cognitivo y que integren, además, narrativas e involucramiento emocional.

Como habíamos mencionado anteriormente, partimos de que el lenguaje conforma un sistema simbólico que conecta diferentes partes de la cognición con las partes emocionales, psicológicas, racionales, perceptuales y motrices. Las actividades retoman la premisa de que solo podremos descubrirnos a nosotros mismos a través de lo que decimos - ser conscientes de que se trata de "nuestro subjuntivo", de "nuestras subordinadas"- si logramos conectarlo con nuestra experiencia emotiva. Las narraciones funcionan como marco, como el dominio, como la Gestalt en la que las explicaciones (en nuestro caso, gramaticales) cobran sentido se integran a la cognición; es decir, constituyen una valiosa y subutilizada herramienta educativa que posibilita la integración de la experiencia en una Gestalt conformada por el devenir existencial propio:

No hay duda: pasamos una gran parte de nuestro tiempo inmersos en historias. En comparación, el tiempo que le dedicamos a los razonamientos lógicos es mínimo. Nuestros juicios intelectuales independientes de un marco narrativo son más bien escasos. No obstante, nos consideramos animales racionales antes 
que animales narrativos. Y este error de apreciación (o esta soberbia) podría explicar algunas de nuestras tribulaciones escolares: nos empeñamos en educar como si fuésemos seres más racionales que narrativos. (Boullosa, 2016: 76)

El tema de los usos de las preposiciones por y para que se presenta a manera de ejemplo (Anexo 1) conjuga metáforas, esquemas preconceptuales, emoción, narración e imágenes animadas. En primer término se explica la diferencia entre ambas preposiciones con base en su origen etimológico. Posteriormente se mapea metafóricamente su significado en los esquemas origen-trayectoriameta y dinámica de fuerzas. Las explicaciones se presentan visualmente, recurriendo a imágenes animadas (gifs) y organizadas de acuerdo con los dominios espacial y temporal. Se incluye también un video (2009) en el que George Lackoff explica de una manera anecdótica la importancia de la metáfora en la cognición. Las actividades están planteadas en términos de preguntas que guían la participación en foros de discusión.

La estructura de la unidad didáctica obedece a la fórmula:

$$
\begin{gathered}
\text { Explicaciones simplificadas (incluso de corte etimológico) + } \\
\text { apropiación cognitiva (a través de metáforas + esquemas + imágenes) } \\
+ \text { narrativas + emoción }=\text { aprendizaje significativo + involucramiento } \\
\text { afectivo + conciencia metalingüística }
\end{gathered}
$$

La discusión que se suscitó en el foro correspondiente a la visualización del video resultó muy enriquecedora porque logró sensibilizar al futuro profesor respecto al potencial de las metáforas y de las narraciones como detonadores de nuestro inventario lingüístico, imaginativo y emocional. Los participantes no vieron pasivamente el video, sino que trataron de relacionarlo con su experiencia personal y de reflexionar sobre la aplicación de los conceptos en el aula de ELE. Este es un ejemplo del cierre de foro elaborado por la profesora: 
Aída abrió el foro comentando sobre multidimensionalidad de la supuestamente lineal trayectoria vital y amorosa, que se puede expresar a través de metáforas. También nos enriqueció con la etimología de la palabra "palabra", valga la redundancia. Su origen nos remite a la relación entre el universo subjetivo e imaginativo que traemos dentro y la posibilidad de gramaticalizarlo en la lengua. Elena abona a estas ideas y trae a colación el ingrediente narrativo. En efecto, estamos inmersos en narrativas hasta cuando dormimos y soñamos.

Eva y Adriana centraron su atención en la utilidad de las metáforas como estrategia didáctica porque con ellas se dinamiza la comprensión del significado. Aída amplió el rango del alcance explicativo de las metáforas a los niveles fónico y léxico.

Finalmente, Adriana aludió a un punto fundamental: la creatividad del lenguaje y la forma como este nos permite ser nosotros. Recuerden la frase de Maturana: "somos en el lenguaje y a través de él" y para lograr este objetivo, las metáforas son un elemento indispensable.

Gracias a todos por sus participaciones. Enfilemos nuestras velas hacia el destino final de este viaje que hemos recorrido por casi cuatro semanas.

La segunda actividad implicó la búsqueda de información. Cabe aclarar que como información de entrada, se presentó un poema, pero no para ser analizado literariamente, sino como estímulo para relacionar significados con el esquema origen-trayectoria-meta y para contextualizar una narración mitológica, la cual, a su vez, sirvió para construir narrativas sobre trayectorias personales. La actividad se planteó en los siguientes términos:

\begin{tabular}{|c|}
\hline a) Investigar sobre el mito al cual remite el poema "Viaje a Ítaca", de \\
Constantin Cavafis. (Esta información de contexto establece el \\
marco para identificar los referentes culturales al leer el poema). \\
b) Reflexionar sobre el significado del tema universal del viaje. \\
c) Responder a dos cuestionamientos: \\
¿Con qué elementos del poema se podría asociar el \\
significado espacial prototípico de las preposiciones por \\
y para? ¿Se podrían asociar algunos otros significados? \\
¿Cómo podría desarrollarse una secuencia didáctica para \\
trabajar ambas preposiciones a partir de estos (u otros) \\
elementos metafóricos e imaginativos?
\end{tabular}


A continuación se transcribe un ejemplo del resumen final, que da una idea del tipo de discusiones que se suscitaron en el foro (un ejemplo de participación individual se presenta en el anexo 2):

Respondiendo de manera puntual a cada una de las preguntas planteadas en relación con los versos del poema y con ejemplos formulados a partir del mito de Ulises, Aída propuso un primer paralelismo entre el viaje y la vida. Elena enriqueció el tema aportando datos sobre el origen etimológico de la palabra viaje. Su análisis nos hace ver que Ítaca está en el origen y en la meta final, de ella sale Ulises y su objetivo es regresar. Se trata de una fuerza que impulsa y que atrae. Adriana, por su parte, nos enriqueció con datos sobre la ubicación mítica de Ítaca, como todo mito universal, resulta ubicuo. Les pido recuerden su afirmación en el sentido de que "la idea positiva en la mente y corazón de cada ser de que en el traqueteo de la vida encontraremos o nos encontrará algo mejor, llámese estabilidad, paz, felicidad, libertad, etc." porque se relaciona también con el tema de la Psicología Positiva que trataremos en la última actividad, en relación con la diferencia entre los verbos copulativos ser y estar.

Eva estableció el paralelismo entre viaje y sueño, entendido como un objetivo que impulsa acciones para conseguirlo. La persecución de ese sueño nos deja también aprendizaje de nuevos conceptos, como el de lotófago, que aparece en la Odisea, pero no en el poema de Cavafis, pero que Eva, al citarlo, nos obligó a reflexionar sobre su significado y a buscar su definición de manera heurística. Esto nos lleva a reflexionar sobre otro punto importante del aprendizaje significativo. A las metáforas y las narrativas hay que añadir la búsqueda y el descubrimiento. Eva también nos compartió ejemplos muy creativos de enunciados con por y para aludiendo a otros personajes de la Odisea. Propone una progresión muy acertada para ir introduciendo los distintos usos de las preposiciones, sin embargo, me quedo con la impresión de que la actividad final que propone no se enfoca suficientemente en los "por" y los "paras" que cada uno debe construir de acuerdo a su historia personal.

Los paralelismos de Claudia nos dejaron claros varios significados de ambas preposiciones en relación con los elementos del poema. Nos compartió también una muy creativa secuencia didáctica que incorpora las narrativas personales, pero como detonantes, no como tarea final (no significa que esté mal, también es válido). 
Aída nos propuso actividades muy dinámicas, que corresponderían a una etapa en la que ya se dio input, se trabajó la forma, se explicaron las reglas de uso, se practicaron la formas. El diario de viaje que mencionó Elena sería una tarea final perfecta para la secuencia.

Ana Laura nos compartió un primer borrador de una secuencia didáctica con el tema de un viaje a Taxco. Presenta actividades de sensibilización, vocabulario, input, un listado de usos, y un contraste con otras preposiciones. Es un buen comienzo, pero tengan en cuenta que, después de este curso, hay que ir más allá. Los puntos básicos de la perspectiva cognitiva son: metáforas visuales explicativas de los fenómenos gramaticales, ubicación espacio-tiempo, narrativas e involucramiento emocional.

Finalmente, Alejandro nos presentó un P.P. con ilustraciones sobre una obra clásica de la literatura china: El viaje al Oeste o Peregrinación al Oeste. Como pueden ver, la Odisea puede no ser un tema cercano a los alumnos, pero el mito de viaje sí lo es, por eso es importante retomar arquetipos universales. La narrativa y las imágenes son muy sugerentes, sin duda constituyen una muy buena base para desarrollar una secuencia didáctica.

Gracias a todos por sus aportaciones.

Aunque las evaluaciones del curso fueron en general buenas, hay que admitir que no resulta fácil para todos los profesores, por razones de distinta índole: manejo de la plataforma Moodle, visualización de videos en inglés, grado de abstracción de las explicaciones, replanteamiento de los conceptos conocidos en otros términos y, sobre todo, el tránsito del diseño de actividades referenciales (por ejemplo de llenado de espacios: "Completa el espacio: Juan va__ la escuela") a actividades que implican búsqueda de información, construcción de contexto, significado, creatividad y, sobre todo, involucramiento afectivo.

Como pudo observarse, se trata de una propuesta que funciona en distintos niveles: cognitivamente suministra información sobre el uso de las preposiciones, pero también propicia reflexiones de carácter metacognitivo (sobre la mejor forma de enseñar y aprender la lengua) y metalingüístico (sobre la manera como cada segmento del sistema lingüístico codifica significados que se relacionan con nuestras estructuras cognitivas básicas).

A manera de colofón, apuntaré un breve comentario sobre mi experiencia como profesora de morfosintaxis a estudiantes mexicanos que se forman como profesores de español. Después de haber lidiado durante años contra el corto 
tiempo, los programas exhaustivos y las actitudes renuentes, he entendido que no puedo agotar en unas cuantas horas el conocimiento de los temas gramaticales, pero sí puedo enamorarlos de su lengua y empezar a remover resistencias haciéndolos conscientes a cada paso de la riqueza conceptual que encierra cada uno de sus segmentos. Este es un ejemplo del tipo de comentarios que hago, en este caso en relación con los verbos copulativos:

Volviendo a la gramática, podemos decir que el sustantivo felicidad denota una sustancia continua, pero al combinarse atributivamente con el verbo copulativo estar, se delimita dentro de un ámbito perfectivo. Se convierte entonces en un estado susceptible de cambiar. Ahora bien, como menciona Alejandro, "es a través de todos estos estar que la vida es". Se trataría de sumar todos los estados transitorios para llegar a ser felices. Al respecto quiero sugerirles que vean una de mis películas favoritas: “Héctor o la búsqueda de la felicidad". Será una buena actividad de relax para concluir con este curso que ha resultado tan demandante:

https://www.youtube.com/watch?v=hB2U8kz1jhA

Pues bien, todo este trasfondo filosófico-psicológico está detrás de nuestros verbos copulativos (uso el posesivo porque espero que a estas alturas ya los sientan como parte de ustedes). Al final de este curso, gracias a los conceptos de la LG hemos logrado desarrollar un poco más nuestra conciencia metalingüística para poder apreciar lo maravilloso que es vivir en una lengua que diferencia entre el Ser y el Estar. Si hacemos un ejercicio de asociación de los usos de ambos verbos copulativos con la pirámide de Maslow, podríamos apreciar su ubicación (recuerden la importancia cognitiva de ubicar en el espacio los conceptos, por abstractos que puedan resultar): estar se asocia con los estratos inferiores, con las necesidades fisiológicas y de seguridad (estar cansado, estar sediento, estar triste); ser se asocia con nuestra naturaleza social, con la necesidad de pertenecer y de ser reconocido por los otros (soy apreciado, soy incluido, etc.) Finalmente, en los estratos superiores requieren de un desarrollo vital; además, el ser ya no requiere de los otros, su autorrealización le permite mirar desde la cúspide de la pirámide, para apoyar a los otros en su trayectoria ascendente hacia la felicidad (ser consciente, ser tolerante, ser empático, etc.). 
Una vez que he logrado seducirlos con mi entusiasmo, lo demás viene por cuenta de ellos. Tienen el resto de su vida para completar el curso, para buscar motu proprio profundizar en los temas que les interesan. Además, la conciencia metalingüística que desarrollan se traduce en profesores apasionados que explican los temas gramaticales del español no como problemas que complican la vida de los estudiantes, sino como representación de conceptualizaciones diversas y ricas que vale la pena conocer tan solo porque existen, porque son diferentes, porque nos abren nuevas posibilidades de comprensión de la realidad.

\section{CONCLUSIONES}

En este artículo se argumentó que la idea de la inutilidad del conocimiento sobre el sistema de la lengua que se ha impuesto en el ámbito educativo en los últimos tiempos se debe a una conceptualización errónea de la gramática (como un conocimiento externo al individuo), así como a las limitaciones de la metodología que se ha aplicado para enseñarla como lengua extranjera y como lengua materna (conocimiento de usuario). La argumentación se desarrolló contrastando las tendencias que agrupan a la gramática como un saber externo al individuo, con aquellas que la conciben como una parte integrante de las estructuras psíquicas que mediatizan nuestra interacción con el mundo; como la herramienta que nos permite conocerlo y acceder a otros mundos a través de recursos como la metáfora. Asimismo, un breve recorrido sobre las tendencias metodológicas de enseñanza evidenció que, aun adoptando la concepción de usuario de la lengua que se deriva del enfoque comunicativo, la gramática es un requisito necesario para acceder a formas más elaboradas de comunicación, sobre todo, escrita.

El desarrollo argumentativo condujo a la justificación de la inclusión de la gramática en el currículo escolar por derecho propio, no solo como apoyo a otras disciplinas; y a la fundamentación teórica de una propuesta para desarrollar cursos de lengua que incorporen explicaciones gramaticales basadas en la LC en conjunción con otros elementos del paradigma cognitivo como las narraciones y el involucramiento afectivo.

Con base en esta argumentación, se fundamentó una propuesta didáctica que contiene explicaciones gramaticales enmarcadas en conceptos de la Lingüística Cognitiva, en conjunción con otros elementos cognitivos que propician el aprendizaje (la narración y la emoción). A manera de ejemplo se presentó una unidad didáctica de un curso en línea destinado a profesores de ELE.

Se concluye que la inclusión de la gramática en el aula de español se justifica plenamente si esta se concibe como un conocimiento valioso en sí mismo, no 
solo porque constituye nuestra forma de ser en el mundo, sino porque es un requisito indispensable para el desarrollo de las capacidades cognitivas y para al robustecimiento de la reflexión y el pensamiento complejo del individuo. El reto radica no solo en cambiar la concepción de la lengua y de la gramática, sino en desarrollar una metodología de enseñanza acorde con los avances científicos sobre el funcionamiento de nuestra cognición humana. Desde esta perspectiva, el objetivo fundamental de cualquier curso de lengua sería desarrollar en los estudiantes una conciencia metalingüística que amplíe sus horizontes hacia conceptualizaciones que abran nuevas posibilidades de comprensión de la realidad y de nuestra forma de ser en ella a través de la lengua. 
V. BiBLIOGRAFÍA

Aıonso, R.; Castañeda, A.; Martínez, P.; Miquel, L.; Ortega, J.y Ruiz, J.P. (2005). Gramática básica del estudiante de español. Barcelona; Difusión, [1ª reimp. 2015].

BILASH, O. y Tulasiewicz, W. (1995) Language Awareness and its place in the CANAdIAN CurRICULum. En Multicultural Education:TheState of the Art. K.A. McLeod (ed.). Winnipeg, Manitoba: Canadian Association of Second Language Teachers, pp. 49-54.

Bachman, L.F. (1990). Fundamental Considerations in Language Testing. Oxford: Oxford University Press.

Bosque, l. (1994). La enseñanza de la gramática (ii), Actas IV Congreso. Asociación para la Enseñanza de Español como Lengua Extranjera (ASELE): Centro Virtual Cervantes.

(2011). Actitudes hacia la lengua que enseñamos. Discurso pronunciado en la Universidad del Salvador, Buenos Aires, 13 de abril de 2011.

(2014). Qué debemos cambiar en la enseñanza de la gramática, ponencia plenaria, I Jornadas GroC (Gramática orientada a las competencias), Universidad Autónoma de Barcelona, enero de 2014.

(2015). Nuevas reflexiones sobre la enseñanza de la gramática. Actitudes frente a contenidos. II Jornadas GrOC (Gramática orientada a las competencias). Universidad Autónoma de Barcelona, 5 de febrero de 2015. Presentación P.P.

(2015b). Ejercicios de análisis sintáctico. Sus clases y su aprovechamiento didáctico. Curso Aplicacions de la gramàtica a l'aula de Secundària i Batxillerat, organizado por CLTICE, Barcelona, 29 de junio - 3 de julio de 2015.

y Gallego, A. (2016). La aplicación de la gramática en el aula. Recursos didácticos clásicos y modernos para la enseñanza de la gramática, Revista de Lingüística Teórica y Aplicada, 54(2), 63-83.

(en prensa): La gramática en la Enseñanza Media. Competencias oficiales y competencias necesarias. Estudio inédito.

BoullosA, P. (2016). El corazón es un resorte. Metáforas y otras herramientas para mejorar nuestra educación. México: Taurus.

CAnAlE, M. and M. Swain (1981). A theoretical framework for communicative competence. En Palmer, A.S., Groot, P.G.y Trosper, S.A. (eds.) The construct validation of tests of communicative competence. Washington, D.C.,TESOL, pp. 31-36.

CASTAÑEDA, A. (2014). Enseñanza de gramática avanzada de ELE. Madrid: SGEL. 
Díaz, C., Gracida, Y., Sule, T. (2014). Luces y sombras de la educación lingüística en México. En La educación lingüística, entre el deseo y la realidad. Lomas, C. (ed.). México: FLACSO y Octaedro.

Doughty, C. y Williams, J. (1998). Focus on form in Classroom Second Language Acquisition. Nueva York: Cambridge University Press.

Evans, V. (2007). A Glossary of Cognitive Linguistics. Edinburgh: Edinburgh University Press. [http://www.vyvevans.net/]

Fornés, M (2013). Categorías cognitivas en ELE, ¿por qué, cuándo y cómo? En Actas del I Congreso Internacional de Didáctica del Español como Lengua Extranjera del Instituto Cervantes de Budapest. [Recuperado el 20 de enero de 2018 de http://cvc.cervantes.es/ensenanza/biblioteca_ele/publicaciones_ centros/PDF/budapest_2013/45_fornes.pdf]

Hymes, D.H. (1972). On Communicative Competence. En J.B. Pride and J. Holmes (eds.) Sociolinguistics. Selected Readings. Harmondsworth: Penguin.

Jurado, M. (2016). Unidad 4. Aplicación de la teoría cognitiva a dos fenómenos gramaticales característicos del español: por y para y el modo subjuntivo. Curso de Gramática Cognitiva, en línea. CEPE-UNAM.

Krashen, S. (1981). Second Language Acquisition and Second Language Learning. Oxford: Pergamon Press.

\section{Longman.}

(1985). The Input Hypothesis Issues and Implications. Londres:

LAKOFF, G. (2009). WGeorge Lakoff on how he started his work on conceptual metaphor, particulary the "LOVE IS A JOURNEY metaphor [Recuperado el 15 de enero de 2018 de https://www.youtube.com/watch?v=Eu-9rpJITY8]

Langacker, R. (2001). Cognitive Linguistics. En M. Putz, S. Niemeir, R. Dirven, (eds.) Applied Cognitive Linguistics I: Theory and Language Acquisition. Berlin: Mouton de Gruyter.

LeE, J.y VanPatten, B. J. (1995). Making Communicative Language Teaching Happen, McGrawHill, Inc., New York.

LomAs, C. (2014). La educación lingüística, entre el deseo y la realidad. Lomas, C. (ed.). México: FLACSO y Octaedro.

Llopis-García, R. (2011). Gramática cognitiva para la enseñanza del español como lengua extranjera. Madrid: Gobierno de España, Ministerio de Educación, Instituto de Formación del Profesorado. Investigación e Innovación Educativa y ASELE, (Monografías, 14).

LloPIS-GaRCía, R. Real, J.M., Ruiz, J.P. (2012). Qué gramática enseñar, qué gramática aprender. Madrid: Edinumen. 
Llopis-García, R. (2016). Using Cognitive Principles in Teaching Spanish L2 Grammar. En Madel Carmen Méndez Santos (coord.). Nuevas perspectivas en la enseñanza del español como lengua extranjera. Hesperia, XIX(2), 2950. [Recuperado el 15 de octubre de 2017 de 1 http://www.coe.int/t/dg4/ linguistic/cadre1_en.asp]

LonG, M. (1991). Focus on form: a design feature in language teaching methodology. En K. D. Bots, C. Kramsh y R. Ginsberg (eds.). Foreign languageResearch in crosscultural perspective ( pp.39-52). Amsterdam: John Bejamins

LORENZO, Francisco J. (2004). Atención a la forma/atención al significado: implicaciones metodológicas para el desarrollo de la competencia gramatical en el aula de español como L2. En La competencia lingüística y comunicativa en el aprendizaje del español como lengua extranjera. Ruhstaller, Stefan y Francisco Lorenzo Borreguillos (coord.). Universidad Pablo de Olavide, EDINUMEN.

LozAno-Zahonero, M. (2016). Reflexión gramatical, uso lingüístico y enseñanza de la gramática en entornos colaborativos. En Geométrica explosión. Estudio de lengua y literatura en homenaje a René Lenarduzzi. Sainz, E. y Solís, Del Barrio, F y Arroyo, I. (eds.), pp. 263-276. [Recuperado el 5 de noviembre de 2017 de http://edizionicafoscari.unive.it/media/pdf/chapter/978-88-6969-0808/978-88-6969-080-8-ch-17.pdf

Maturana, H. y Varela, V. (1996). El árbol del conocimiento. Chile: Editorial Universitaria.

Munguía, I. (2014). Comentarios y recomendaciones sobre la enseñanza del español como lengua materna del sistema Educativo Nacional. En Habilidades lingüísticas de los estudiantes de primer ingreso a las Instituciones de Educación Superior", González, R. (coord.). México: ANUIES.

(2016). Gramática de la lengua española: clases de palabras. México: Gedisa, Universidad Autónoma Metropolitana (UAM).

MuÑoz, C. Semántica cognitiva: Modelos Cognitivos y Espacios Mentales. En A parte Rei. Revista de Filosofía, no. 43, 2006. [Recuperado el 20 de noviembre de 2017 de http://serbal.pntic.mec.es/ cmunoz11/carlos43.pdf]

Perales, J (2004). La conciencia metalingüística y el aprendizaje de una L2/LE, en J. Sánchez Lobato y Santos Gargallo (dir). Vademecum para la formación de profesores. Enseñar español como segunda lengua (L2)/lengua extranjera (LE) (329-349). Madrid: SGEL.

MARTín Peris, E. (2004). La subcompetencia lingüística o gramatical. En Sánchez Lobato, J. y Santos Gargallo, I. Vademécum para la formación de profesores. Enseñar español como segunda lengua (L2) / lengua extranjera (LE) (467-489). Madrid: SGEL. 
Paradis, M. (1994). Neurolinguistic aspects of implicit and explicit memory: Implications for bilingualism and SLA". En N. Ellis (ed.). Implicit and Explicit Learning of Languages (393-419). California: Academic Press.

Pfleger, S. (2016). Programa del Seminario Sociedad, cultura, pensamiento y complejidad social: El lenguaje como sistema complejo adaptativo. Centro de Enseñanza de Lenguas Extranjeras (Línea de investigación: Lenguaje, pensamiento y complejidad social), Centro de las Ciencias de la Complejidad (C3, Sociocomplejidad).

RAE (2001). Diccionario de la lengua española. Real Academia de la Lengua Madrid. [22.a ed.]

RAE-ASALE (2011). Nueva gramática básica de la lengua española. Real Academia Española y Asociación de Academias de la Lengua Española. Madrid: Espasa.

Romo, F. (2015) La instrucción gramatical y la lengua materna en la era postmétodo, Marcoele, 21.

Ruiz-Campillo. J. (2007). Entrevista a José Plácido Ruiz Campillo: Gramática cognitiva y ELE. En marcoELE, revista de didáctica ELE, no. 5. [Recuperado el 15 de julio de 2017 de http://marcoele.com/descargas/5/entrevista_jp.pdf]

TolCHINSKY, S. (2011). La lengua como herramienta de aprendizaje. En Lengua castellana y literatura. Complementos de formación disciplinar. Ruiz Bikandi, U. (coord.). Madrid: Grao, Gobierno de España. Ministerio de Educación.

SELINKER, L. (1972). “Interlanguage”, en IRAL, X (2), 209-231.

VanPatten, B. (1996). Input Processing and Grammar Instruction. New Jersey: Ablex Publishing Corporation, Norwood. 


\section{Gramática cognitiva}

Unidad 4. Aplicación de la teoría cognitiva dos fenónemos gramaticales característicos de español: por y para y el modo subjuntivo

\section{Presentación}

, En las dos últimas unidades del curso intentaremos aplicar algunos conceptos de la GC a la explicación de cuatro de los fenómenos más característicos de la enseñanza gramatical de E/LE. Se trata de un intento porque hasta la fecha no existe un tratado de GC diseñado para tal fin, aunque -como habrán podido apreciar en el video de la unidad 3 y en las lecturas de las anteriores unidades- existen avances desarrollados principalmente en España. Cabe señalar, sin embargo, que la desvinculación entre el conocimiento gramatical teórico y su aplicación a la enseñanza no es exclusivo de la lengua española:

Los lingüistas a menudo se quejan de que los métodos que se usan en las clases de lengua extranjera no se corresponden con lo que ellos investigan sobre el lenguaje, y lamentan que sus conocimientos se pasen por alto en el diseño de métodos y actividades. Por otra parte, los profesores de lenguas extranjeras se quejan de que los conocimientos de los lingüistas simplemente son poco prácticos con los asuntos de clase, porque en las teorías lingüísticas actuales no se pueden encontrar los elementos que puedan ser útiles en el día a día y que proporcionen directrices firmes sobre las que basar los métodos didácticos (Achard, 2004: 167).

En esta cuarta unidad presentaremos algunos esquemas y modelos que intentan dar cuenta de dos fenómenos gramaticales característicos del español: las preposiciones por y para y el modo subjuntivo.

- Las actividades consistirán en reflexionar sobre la posibilidad de aterrizar estos conceptos en explicaciones que eventualmente pudieran integrarse en materiales didácticos (trabajados preferentemente con una metodología congruente, como podría ser la Teoría del procesamiento del input plasmada en textos como la Gramática básica del estudiante de español, de Alonso Raya et al.).

\section{Objetivo particular}

Al término de la unidad, el estudiante: 
Aplicará algunos conceptos de la teoría cognitiva a la explicación de dos fenómenos gramaticales característicos del español: preposiciones por /para y usos del modo subjuntivo.

\section{Tema 1. Las preposiciones por y para}

\section{Objetivos específicos}

Al término del tema, el estudiante:

Diferenciará algunos usos de las preposiciones por y para con base en dos esquemas cognitivos básicos (dinámica de fuerzas y origen-trayectoria-meta) y en los conceptos de «dominio» y «subjetivización»

, Aplicará el concepto de "Modelo Dinámico Evolutivo» a la explicación de algunos usos del subjuntivo.

, Reflexionará sobre el potencial explicativo de las metáforas integradas en unidades gestálticas.

\section{Contenido}

Como se recordará, en la LC se concibe que el significado de una expresión incorpora la construcción convencional de imágenes; es decir, incorpora una manera particular de procesar y construir el contenido conceptual de los dominios que evoca una expresión lingüística. Los «dominios» son estructuras de conocimiento (experiencias mentales, espacios representacionales o conceptos) necesarias para caracterizar semánticamente una expresión lingüística o unidad semántica. Los dominios pueden ser básicos o abstractos.

Los primeros se derivan de la experiencias sensoriales y subjetivas (espacio, color, temperatura, dolor, tiempo, emoción, etc.). Los dominios abstractos son más complejos, no están anclados directamente en la experiencia corporal; por ejemplo, el sistema de RELACIONES DE PARENTESCO es el dominio o fondo sobre el cual el significado de la palabra padre es caracterizado; mano evoca como dominio BRAZO; dedo al dominio MANO, etc.

La preposición por, en su significado prototípico, "indica el espacio que se recorre para llegar de un sitio a otro: Vamos para Alicante por la carretera de la costa. (Alonso, et al., 2015: 207). La preposición para, "indica el objetivo final al que se dirige algo" (Ibid.). Aplicando el esquema cognitivo básico de "origen-trayectoria-meta" el significado de por se representaría de esta manera: 

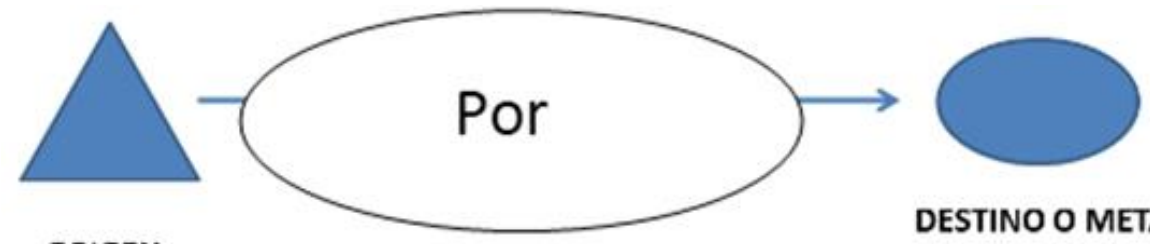

DESTINO O META

ORIGEN

En cuanto al origen etimológico de ambas preposiciones, en el Diccionario Gramatical, de Martínez Amador (1953) se consigna que:

POR. - Es una de las preposiciones latinas que se conservan después de haber sufrido la metátesis de la $r$ (lat.pro). Combinada con la preposición también latina ad, dio la combinación pro ad, que en nuestro romance fue por a, que llegó a la soldadura y se convirtió luego en para.

Corresponde por a las preposiciones latinas pro y per, las cuales se han confundido en la mayor parte de las lenguas romances. Martínez Amador (1953: 1127)

La preposición latina pro significaba en favor de, mientras que per significaba a través de, por medio de, durante. La fusión de ambas formas dotó de una incipiente direccionalidad al significado de trayectoria aportado por per. Como se explica en la cita de Martínez Amador, en una subsecuente etapa evolutiva, se reforzó el significado direccional mediante la adición de la preposición ad, con lo cual se dio origen a la variante pora. Finalmente, la preposición pora se convirtió en para:

PARA. - Esta preposición representa un caso de soldadura quizá único en nuestra lengua. Su forma primitiva era pora como la vemos en el Cantar del Cid: "pora las visitas se adovaban" y tenía varios significados. Puede proceder esta soldadura de los casos en que la preposición por iba acompañada de un complemento regido por la preposición. Se trata de frases en que por tiene también idea de finalidad. Asimismo en Mio Cid leemos (701): «por a Mio Cid e a los sos a manos los tomar», según que hace Menéndez Pidal en su edición crítica del Cantar, ya que en la paleografía figura porjunto. De esta construcción de complemento con a se ven también ejemplos, como: "por a mi guerrear» (Berceo). Pero cuando las dos preposiciones se encuentran juntas sin diferencias de régimen, forman ya un todo, que luego se convierten en para. La forma para aparece en el Mio Cid dos veces, una de ellas en lugar de par, equivalente a por. Su etimología es pro ad. (Martínez Amador, 1953: 1066)

Dicha fusión semántica se representaría de la siguiente manera: 


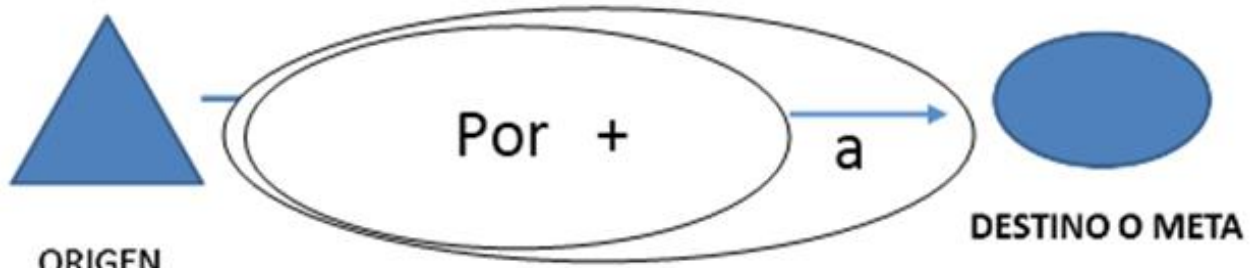

Hay que tomar en cuenta que una explicación de esta naturaleza tiene como base el concepto de «subjetivización» ( $c f$. el PDF de la Unidad III, actividad 6, pp. 69-73); es decir, la idea de que "hablamos del mundo como si estuvieran ocurriendo cosas que, al representárnoslo, solo ocurren en nuestra mente" (Castañeda et al. 2014: 69).

Como recordarás, con base en el concepto de «subjetivización», Castañeda et al. explica el significado de la preposición por en los siguientes términos:

... a veces estas [las preposiciones] se refieren a orientaciones que describen procesos mentales que se siguen en la concepción o representación de alguna situación objetiva. Por ejemplo, la preposición por en su valor prototípico espacial básico, se refiere a la relación entre un recorrido o movimiento y el trayecto que se recorre para llegar de un origen a un destino (Ha cruzado por el paso de peatones). Sin embargo, también se usa para hablar de la localización indeterminada de cierto objeto respecto de cierto espacio, como en La pelota está por ahí detrás. En realidad, por no puede señalar un trayecto objetivo seguido por el movimiento de la pelota, porque la pelota no tiene por qué estar en movimiento, sino más bien el movimiento subjetivo que debe recorrer el conceptualizador para encontrar la pelota. Funcionalmente, podríamos parafrasear la frase diciendo algo así como "Si vas por ahí detrás, encontrarás la pelota en algún punto del trayecto de tu recorrido" (Castañeda et al. 2014: 71).

Las siguientes animaciones tratan de representar contrastivamente los significados básicos de las preposiciones por y para, tomando como base el tipo de verbos con los que se combinan y las características semánticas del Gpo. Nom. que funciona como término.

Gpo. Nom / Término que denota espacio (dominio espacial)

Indica tránsito a través de un lugar (con verbos de movimiento):
Indica destino (con verbos de movimiento): 


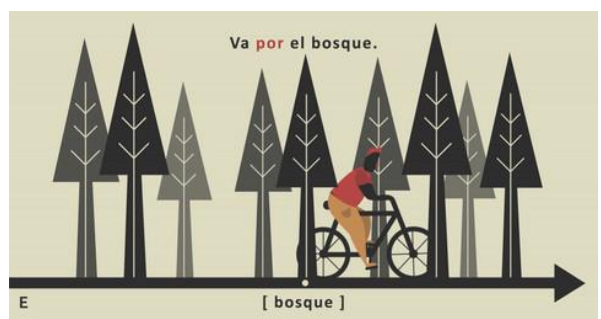

Indica lugar aproximado en el que se realiza una acción:

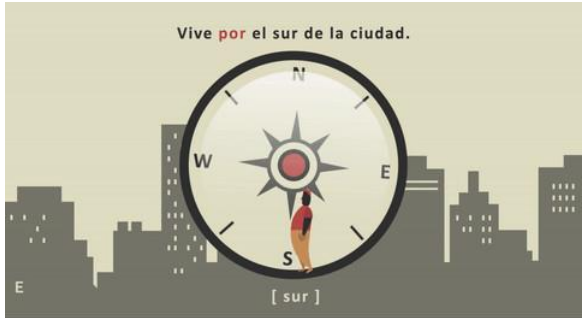

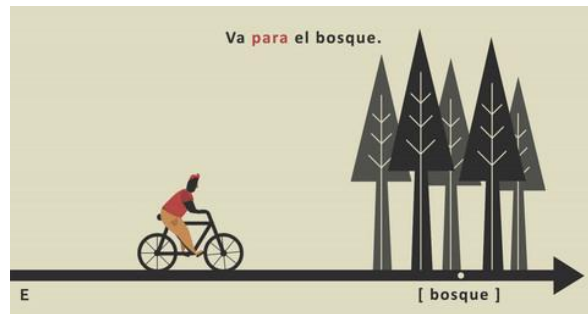

Cuando el dominio es espacial, la combinación sintáctica de la preposición por arroja varias posibilidades:

Verbo de movimiento + por + Gpo. Nom. que denota lugar = trayectoria a través del lugar: va por el bosque.

Verbo de estado + por+ Gpo. Nom. que denota un punto específico anclado en la trayectoria espacial $=$ direccionalidad irregular (no lineal) dentro de una porción de la trayectoria y en torno a dicho punto específico (en este caso su significado puede ser parafraseado utilizando el adverbio aproximadamente): Vive por el sur de la ciudad.

Por otro lado, la preposición para perfila la meta, el punto de destino de la trayectoria. Al igual que en dominio temporal, lo relevante a la interpretación semántica es que la trayectoria espacial se relega a la base y se perfila el punto de llegada (y en este caso su significado puede ser parafraseado utilizando la preposición hacia): va para el bosque (va hacia el bosque).

Se combina preferentemente con verbos de movimiento. 
Gpo. Nom/Término que denota tiempo (dominio temporal)

Indica duración, temporalidad limitada:

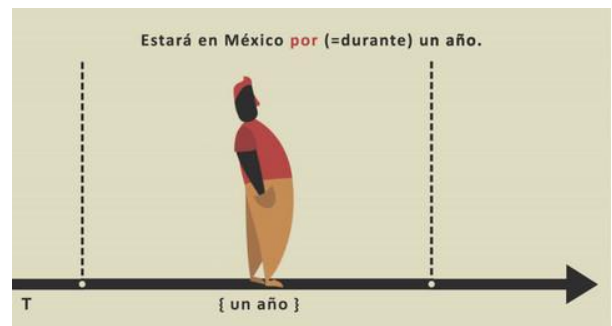

Indica tiempo aproximado en el que se realiza una acción:

Estará aquí por (aproximadamente) el 15 de mayo.

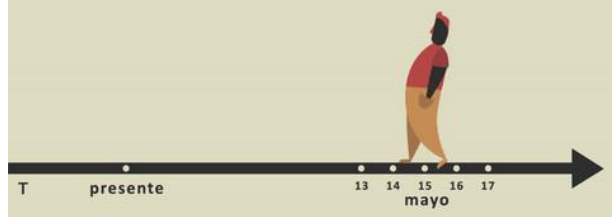

Indica límite temporal en el futuro:

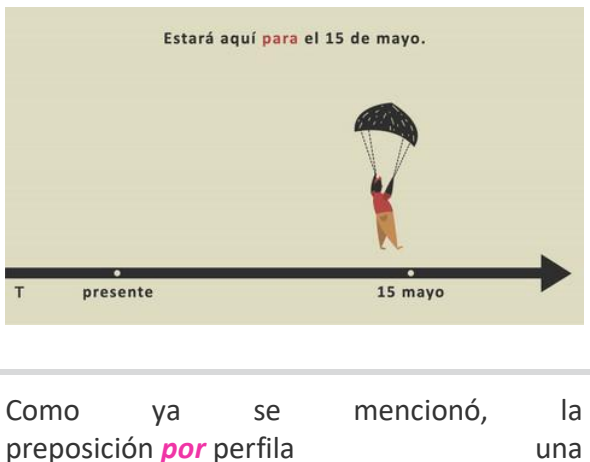

trayectoria. Cuando el dominio es temporal, puede tener como término un Gpo. Nominal que denota un periodo, concebido como una porción lineal de dicha trayectoria (y en ese caso su significado es equivalente al de la preposición durante):estará en México por un año, viajará por un mes, reposará por dos horas, etc.

Cuando el Gpo. Nom./Término denota un momento, un punto específico anclado en la trayectoria temporal, el significado de por corresponde al de una direccionalidad irregular (no lineal) dentro de una porción de trayectoria y en torno a dicho punto específico (en este caso su significado puede ser parafraseado utilizando el adverbio aproximadamente): estará aquí por mayo, vendrá por el 15 de mayo, más o menos por esas fechas, etc.

Por otro lado, la preposición para perfila la 
meta, el punto de destino de la trayectoria. Dicha meta puede ser puntual (p. ej. Para el 15 de mayo) o tener duración interna ( $p$. ej. para el próximo año), lo relevante a la interpretación semántica es que la trayectoria temporal se relega a la base y se perfila el punto de llegada.

Fuera de los dominios espacial y temporal, el Gpo.Nom./Término puede denotar entidades de primero o de segundo orden. Surgen entonces significados causales y de finalidad que pueden ser explicados metafóricamente echando mano del esquema básico de fuerzas dinámicas. Desde esta perspectiva, la preposición por representa una fuerza dinámica que "empuja" la acción denotada por el verbo a lo largo de la trayectoria, mientras para señala el beneficiario, el objetivo o la finalidad que "jala" la fuerza dinámica.

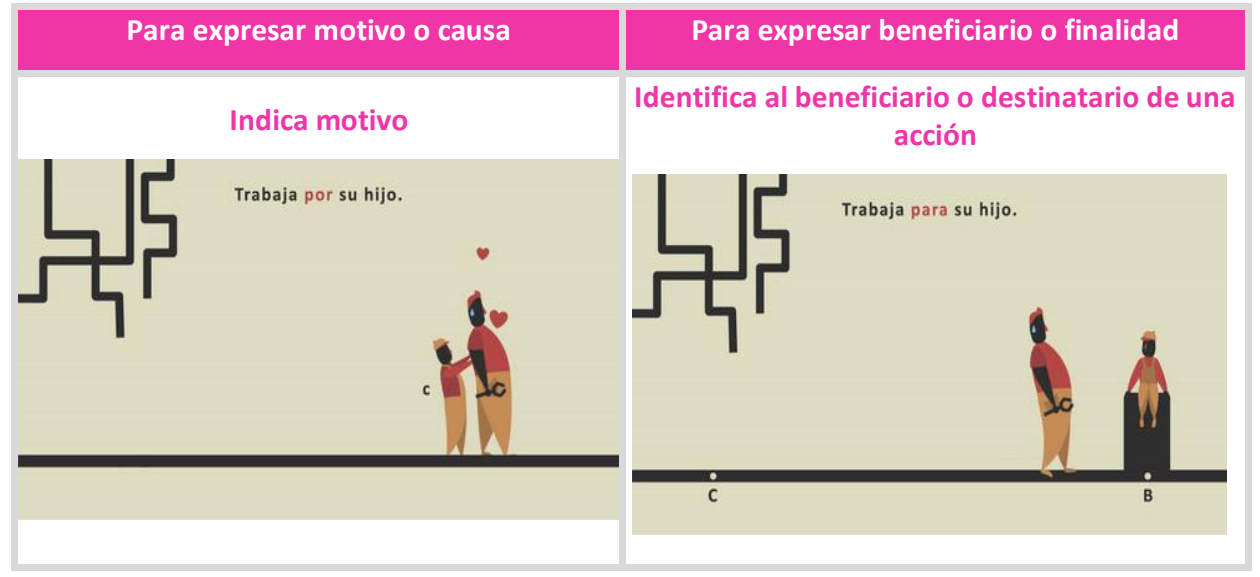

Cuando el Gpo.Nom. / Término denota una entidad de primer orden (aquella que ocupa un lugar en el espacio), la preposición por ejerce una fuerza precedente que "empuja" la acción del verbo: trabaja por su hijo, se sacrifica por el equipo, llora por su madre.

Cuando el Gpo.Nom. / Término denota una entidad de primer orden (aquella que ocupa un lugar en el espacio) la preposición para ejerce una fuerza desde el beneficiario que atrae o "jala" la acción del verbo: trabaja para su hijo, lo compró para sus padres, las imprimó para el grupo. 


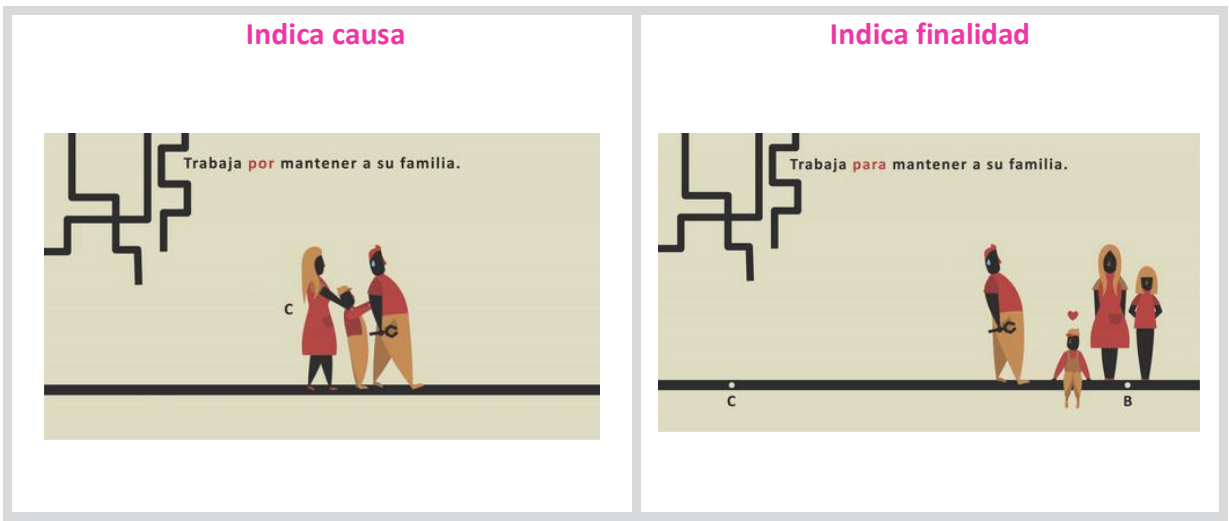

Cuando el Gpo.Nom./Término corresponde a una nominalización o a una oración (una entidad de segundo orden que ocupa un lugar en el tiempo), la preposición porrepresenta la circunstancia causal, la fuerza precedente que "empuja" la acción del verbo. Obviamente, cuando se trata de oraciones, la preposición por se transforma en la conjunción subordinanteporque: llora por la enfermedad de su madre, trabaja por mantener a su familia, se sacrifica porque quiere obtener un buen puesto de trabajo.

Cuando el Gpo. Nom./Término corresponde a una nominalización o a una oración (una entidad de segundo orden que ocupa un lugar en el espacio) la preposición para representa el punto de atracción, la finalidad que "jala" la acción denotada por el verbo: trabaja para la educación de su hijo, lo compró para que sus padres vivan tranquilos, las imprimó para facilitar la tarea del grupo.

Existen otros usos de pory para que pueden ser considerados extensiones de su significado espacial prototípico. Por ejemplo, el uso de para en "comparaciones con el estándar" (p. ej. para ser modelo, viste muy mal; es muy lista para su edad, etc.), podría explicarse interpretando el Gpo.Nom./Término como un punto de referencia, el estándar a partir del cual se compara a otra entidad.

\section{Aplicación pedagógica}

Ignacio Bosque, el gramático en lengua española más importante de los últimos tiempos, afirma que los profesores de lengua hemos sido incapaces de transmitir a los estudiantes que la lengua, a diferencia de otras disciplinas que se enseñan en la escuela, no es un saber externo que se aprende solo para pasar exámenes. Afirma que:

Cuando el profesor de ciencias naturales explica en clase la estructura del corazón humano, el alumno sabe que le están hablando de su corazón. 
Cuando el profesor de lengua explica en clase la estructura de las subordinadas sustantivas, el alumno no piensa ni por un momento que le estén hablando de sus subordinadas sustantivas.

$[\ldots]$

Se dice que los adolescentes se caracterizan por juzgar el mundo que los rodea como un conjunto de sistemas impuestos y arbitrarios. A nosotros nos corresponde la tarea de mostrarles que su lengua les pertenece y que analizarla no es más que un recurso, entre otros posibles, para que lleguen a aprender algo sobre sí mismos. (Bosque, 2015).

Pero no se trata solamente sensibilizar a nuestros estudiantes extranjeros para pensar en español, sino de sensibilizarnos y concientizarnos nosotros mismos de toda la información que codificamos con nuestras palabras, nuestra entonación, el orden sintáctico que utilizamos, etcétera (como recordarán, ese fue el objetivo de la primera actividad de este curso).

Como profesores de español a estudiantes extranjeros hemos desarrollado en cierta medida una capacidad de reflexionar metalingüísticamente sobre el sistema, sin embargo, ni los profesores ni los estudiantes hablantes nativos del español lo han hecho; ellos experimentan el aprendizaje de la lengua como algo externo, no se dan cuenta de que nosotros somos nuestra lengua; es nuestra forma de ser en el mundo. Como dice Humberto Maturana, "somos en el lenguaje y a través de él":

Nos realizamos en un mutuo acoplamiento lingüístico, no porque el lenguaje nos permita decir lo que somos, sino porque somos en el lenguaje, en un continuo ser en los mundos lingüísticos y semánticos que traemos a la mano con otros. Nos encontramos a nosotros mismos en este acoplamiento, no como el origen de una referencia ni en referencia a un origen, sino como un modo de continua transformación en el devenir del mundo lingüístico que construimos con los otros. (Maturana/Varela,1996: 154)

En estas dos últimas unidades del curso exploraremos caminos para apropiarnos de nuestra lengua y para reflexionar sobre cómo podemos hacer que nuestros estudiantes lo hagan. No se trata de una metodología didáctica, sino de un ejercicio de imaginación que conjuga la narración con explicaciones gramaticales basadas en metáforas cognitivas.

Por otra parte, en su libro, El corazón es un resorte. Metáforas y otras herramientas para mejorar nuestra educación, Pablo Boullosa propone que las mejores herramientas para el aprendizaje no son los flamantes dispositivos electrónicos, sino recursos de nuestro inventario lingüístico, imaginativo y emocional. El autor coincide con la perspectiva cognitiva, ya que plantea que las metáforas son los recursos por excelencia para comprender la realidad y compartirla; asimismo, concibe la narración como una segunda herramienta educativa, como un factor integrador de la experiencia en una Gestal existencial:

No hay duda: pasamos una gran parte de nuestro tiempo inmersos en historias.

En comparación, el tiempo que le dedicamos a los razonamientos lógicos es mínimo. Nuestros juicios intelectuales independientes de un marco narrativo son más bien escasos. 
No obstante, nos consideramos animales racionales antes que animales narrativos. $Y$ este error de apreciación (o esta soberbia) podría explicar algunas de nuestras tribulaciones escolares: nos empeñamos en educar como si fuésemos seres más racionales que narrativos. (Boullosa, 2016: 76)

Las narraciones funcionan como marco ${ }^{1}$, como el dominio, como la Gestalt en la que se integran cognitivamente y cobran sentido las explicaciones.

En las dos últimas unidades de este curso, se proponen actividades para experimentar y reflexionar sobre la aplicación de la perspectiva metafórica de la GC en conjunción con la imaginación poética y narrativa. Se trata de explorar un camino inédito y de valorar su viabilidad pedagógica.

\section{Actividad 1. Foro "Reflexión sobre cómo trabajar las preposiciones por y para"}

Investigue sobre el mito al cual remite el siguiente poema de Constantin Kavafis:

\section{Viaje a ítaca}

Cuando emprendas el viaje hacia Ítaca, ruega que tu camino sea largo

y rico en aventuras y descubrimientos.

No temas a lestrigones, a cíclopes o al fiero Poseidón;

no los encontrarás en tu camino

si mantienes en alto tu ideal,

si tu cuerpo y alma se conservan puros.

Nunca verás los lestrigones, los cíclopes o a Poseidón,

si de ti no provienen,

si tu alma no los imagina.

Ruega que tu camino sea largo,

que sean muchas las mañanas de verano,

cuando con placer, llegues a puertos

\footnotetext{
${ }^{1}$ El término marco (trabajado por Fillmore, 1975 y 1985, y Lakoff, (1987) ha recibido otras denominaciones dentro de la LC, como por ejemplo «modelo cognitivo idealizado» (término usado por los dos autores anteriores) «dominio cognitivo» (importado desde la psicología cognitiva y trabajado por Langacker, 1987 y 1991), «guión» o «esquema» (explicados en detalle dentro de Ungerer \& Schmid 1996). Todos, sin embargo, no existen valores absolutos de significado para cada palabra, sino que cada hablante, según su experiencia sensorial y conocimiento del mundo, construye toda una serie de informaciones interconectadas que dan sentido y completan su valor para todos los contextos de uso posibles, haciéndola transferible a otros contextos aún sin crear. (Llopis, 2011: 92)
} 
que descubras por primera vez.

Ancla en mercados fenicios y adquiere cosas bellas:

madreperla, coral, ámbar, ébano

y voluptuosos perfumes de todas clases.

Compra todos los aromas sensuales que puedas;

ve a las ciudades egipcias y aprende de los sabios.

Siempre ten a Ítaca en tu mente;

llegar allí es tu meta; pero no apresures el viaje.

Es mejor que dure mucho,

mejor anclar cuando estés viejo.

Pleno con la experiencia del viaje

no esperes la riqueza de Ítaca.

Ítaca te ha dado un bello viaje.

Sin ella nunca lo hubieras emprendido;

pero no tiene más que ofrecerte,

y si la encuentras pobre, Ítaca no te defraudó.

Con la sabiduría ganada, con tanta experiencia,

habrás comprendido el significado de las ítacas.

1. Reflexione sobre el significado del tema universal del viaje.

2. ¿Con qué elementos del poema se podría asociar el significado espacial prototípico de las preposiciones por y para? ¿Se podrían asociar algunos otros significados?

3. ¿Cómo podría desarrollarse una secuencia didáctica para trabajar ambas preposiciones a partir de estos (u otros) elementos metafóricos e imaginativos?

Participe en el foro de unidad con sus reflexiones.

Una vez enviada su participación, vea el siguiente video de Lakoff

\section{https://youtu.be/Eu-9rpJITY8}


ANEXo 2

(EJEMPLO DE UNA PARTICIPACIÓN EN FORO)

Hola a Todos:

Contesto las preguntas de la Actividad 1. Reflexión sobre cómo trabajar las preposiciones por y para

1. Reflexione sobre el significado del tema universal del viaje.

El tema del viaje normalmente se identifica con la vida, que, como todo camino o trayecto, puede tener dificultades y alegrías que templan el carácter para actuar con sabiduría cada vez que se adquiere experiencia, y hacernos comprender que toda prueba proviene de nosotros mismos, toda vicisitud o "cíclope" llega si nuestra alma la imagina (versos 9 y 10). El poema hace referencia al viaje de Ulises a Ítaca, pero también se puede interpretar como el viaje interior que tenemos que hacer todos para desarrollarnos, crecer con sabiduría y llegar a nuestras metas. El poema es una invitación para que en nuestro viaje (vida) descubramos, veamos, aprendamos, disfrutemos.

2. ¿Con qué elementos del poema se podría asociar el significado espacial prototípico de las preposiciones por y para? ¿Se podrían asociar algunos otros significados?

El significado espacial prototípico de las preposiciones por y para se relacionan muy bien con el poema por su idea del viaje para ĺtaca y los problemas que debió pasar Ulises por el camino. Además, hay algunos versos en los que podrían sustituirse algunas preposiciones por por y para

1. Para: Cuando emprendas el viaje hacia [para] Ítaca (verso 1)

2. Por: no los encontrarás en [por] tu camino (verso 2)

3. No temas a lestrigones, a cíclopes o al fiero Poseidón; no los encontrarás en [por] tu camino... (versos 4 y 5 ).

4. Por: Ve a [por] las ciudades egipcias y aprende de los sabios (verso 15). Así que tomar como tema el viaje en clase para aprender la distinción de estas preposiciones me parece muy acertado. 
También podrían asociarse los significados de causa, finalidad, destinatario, tiempo.

1. Ulises viajó por mucho tiempo.

2. Ulises volvió a Ítaca para el final de su vida.

3. Ulises viajó por una causa mayor a sus deseos.

4. Ulises llevó tesoros para Penélope.

Asimismo, me parece pertinente añadir el significado de sustitución de la preposición por, aunque no está la imagen Por ejemplo:

Ulises, en momentos difíciles, quería cambiar su vida por otra.

¿Cómo podría desarrollarse una secuencia didáctica para trabajar ambas preposiciones a partir de estos (u otros) elementos metafóricos e imaginativos?

Se podría trabajar la idea del amor, basarnos en el tema del video. En español hay muchos enunciados que hablan de amor y usan las preposiciones por y para. Anexo un borrador con ideas muy generales de una posible secuencia didáctica. 
ACtividAd 1. Foro "ReflexIÓN SOBRE CÓMO tRABAJAR LAS PREPOSICIONES POR Y PARA"

\section{SECUENCIA DIDÁCTICA: AMOR POR/PARA TI}

Objetivo:

- Desarrollar la comprensión de las preposiciones por y para a través del uso de matáforas.

Destinatarios: estudiantes de nivel A2 (básico 4)

CONTENIDOS TEMÁTICOS

Preposiciones por y para con referencia a un espacio.

- Preposición por como trayectoria a través del lugar. Ejemplo: va por el bosque.

- Preposición por como punto específico anclado en la trayectoria espacial = direccionalidad irregular (no lineal) dentro de una porción de la trayectoria y en torno a dicho punto específico (sinónimo del adverbio aproximadamente): Vive por el sur de la ciudad.

- Preposición para como la meta, el punto de destino de la trayectoria. Trayectoria espacial: base relegada y dirección hacia el punto de llegada (sinónimo de la preposición hacia): va para el bosque (va hacia el bosque).

- Preposición por, motivo o causa.

- Preposición para, beneficiario o finalidad.

- Preposición por, duración o temporalidad ilimitada.

- Preposición para, límite temporal en el futuro.

- Preposición por, sustitución.

\section{ACTIVIDADES}

\begin{tabular}{|l|l|l|}
\hline Apertura & Desarrollo & Cierre \\
\hline Lluvia de ideas: pensar & I. Leer un breve texto & Escribir una carta \\
en frases que usan en su & sobre el amor. & para expresa amor \\
lengua para expresar amor & Dicen por ahí que en toda & a un ser imaginario \\
o referirse al amor: Ich liebe & en toda historia de amor & o un ser querido \\
dich (alemán), I love you, I & siempre hay algo que & (mamá, papá, hijos, \\
am crazy about you... & nos acerca a la eternidad & pareja). \\
E a la esencia de la vida, & \\
El maestro retroalimenta & porque las historias de \\
con las frases más comunes & amor encierran en sí & \\
en español. Te quiero, te & todos los secretos del & \\
amo, te aprecio, me gustas. & mundo. También se dice & \\
Muero por ti, lo hago por & que siempre existe en el & \\
amor, amor por siempre... &
\end{tabular}




\begin{tabular}{|c|c|c|}
\hline \multicolumn{3}{|c|}{ Actividades } \\
\hline Apertura & Desarrollo & Cierre \\
\hline & $\begin{array}{l}\text { mundo una persona } \\
\text { especial para otra, una } \\
\text { que espera a otra, ya sea } \\
\text { por los desiertos o por } \\
\text { las grandes ciudades. Y } \\
\text { cuando esas personas } \\
\text { se cruzan y sus ojos se } \\
\text { encuentran, ya no será } \\
\text { necesario viajar por } \\
\text { todo el mundo, todo el } \\
\text { pasado y todo el futuro } \\
\text { pierden completamente } \\
\text { su importancia y solo } \\
\text { existe aquel momento; } \\
\text { solo es real el espacio } \\
\text { que crearon para ellos. } \\
\text { En el amor no existen } \\
\text { reglas. Podemos } \\
\text { intentar guiarnos por } \\
\text { un manual, controlar } \\
\text { el corazón, tener para } \\
\text { cada encuentro amoroso } \\
\text { una estrategia de } \\
\text { comportamiento... Pero } \\
\text { todo eso es una tontería. } \\
\text { El amor será por siempre } \\
\text { un dulce misterio. (...) } \\
\text { [Adaptación de un } \\
\text { fragmento de } A \text { orillas del } \\
\text { río de piedra me sentéy } \\
\text { lloré, de Paulo Cohelo]. } \\
\\
\text { II. Reflexionar sobre } \\
\text { el uso que se le dio a } \\
\text { los enunciados con las } \\
\text { preposiciones por y para. }\end{array}$ & \\
\hline
\end{tabular}




\section{Actividades}

\begin{tabular}{|c|c|c|}
\hline Apertura & Desarrollo & Cierre \\
\hline & $\begin{array}{l}\text { III. Elige el enunciado que } \\
\text { corresponda con la imagen que se } \\
\text { presenta en cada ejercicio. } \\
\text { a. Una persona especial para otra } \\
\text { b. Una persona especial por otra. } \\
\text { Dibujo de persona que se dirige } \\
\text { para el desierto } \\
\text { a. Por los desiertos y las grandes } \\
\text { ciudades } \\
\text { b. Para los desiertos y las grandes } \\
\text { ciudades. } \\
\text { Dibujo de una persona que viaja } \\
\text { por todo el mundo } \\
\text { a. Viajar por todo el mundo } \\
\text { b. Viajar para todo el mundo* } \\
\text { (aquí habría que señalar que } \\
\text { no es posible decir esto por } \\
\text { el significado del verbo que } \\
\text { no acepta el significado de la } \\
\text { proposición como beneficiario o } \\
\text { destinatario) } \\
\text { a.El espacio que crearon por ellos. } \\
\text { b. El espacio que crearon para ellos. } \\
\text { a.En el amor no es posible guiarnos } \\
\text { por un manual... } \\
\text { b. En el amor no es posible guiarnos } \\
\text { para un manual... }\end{array}$ & \\
\hline
\end{tabular}




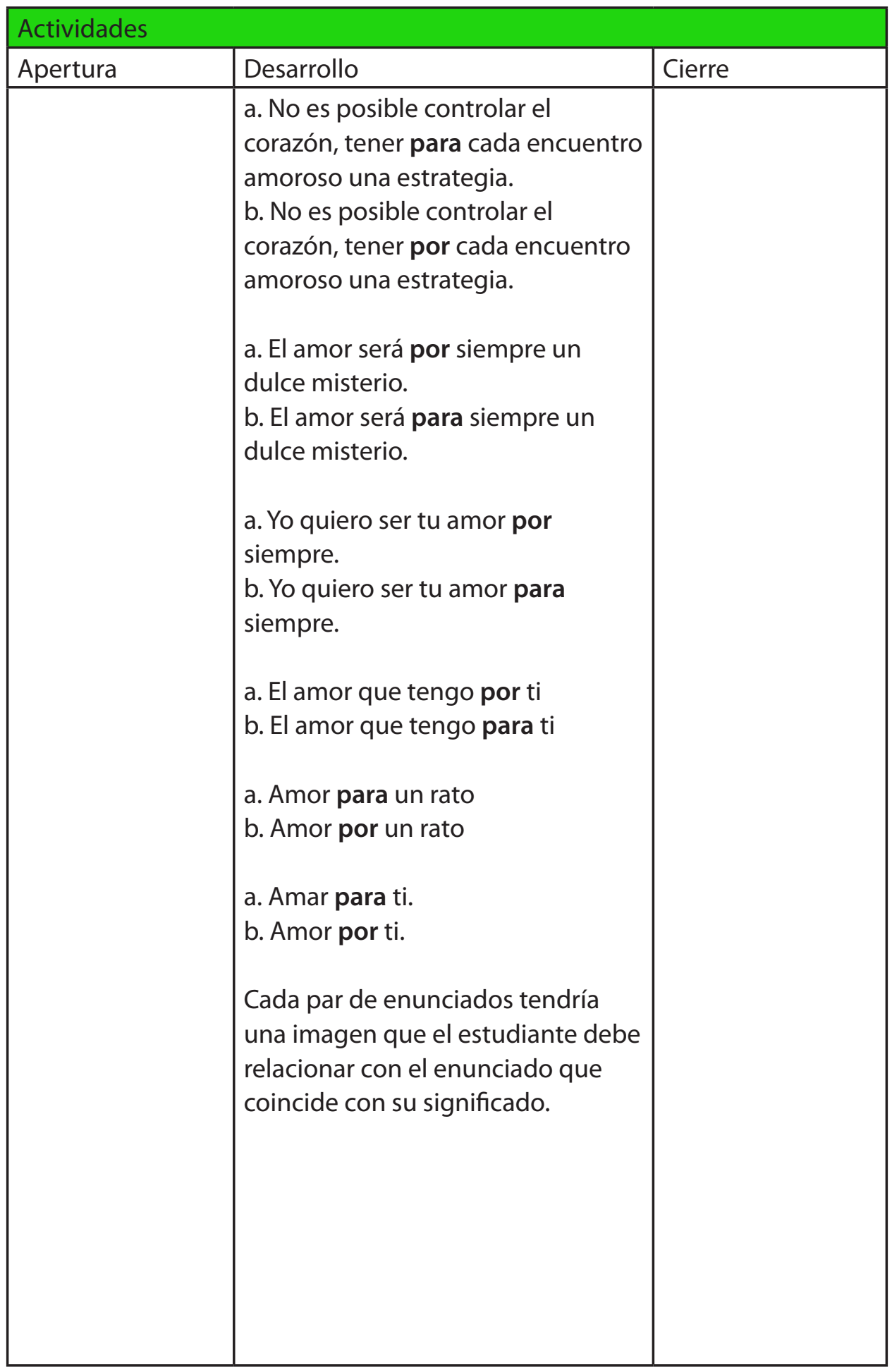


